
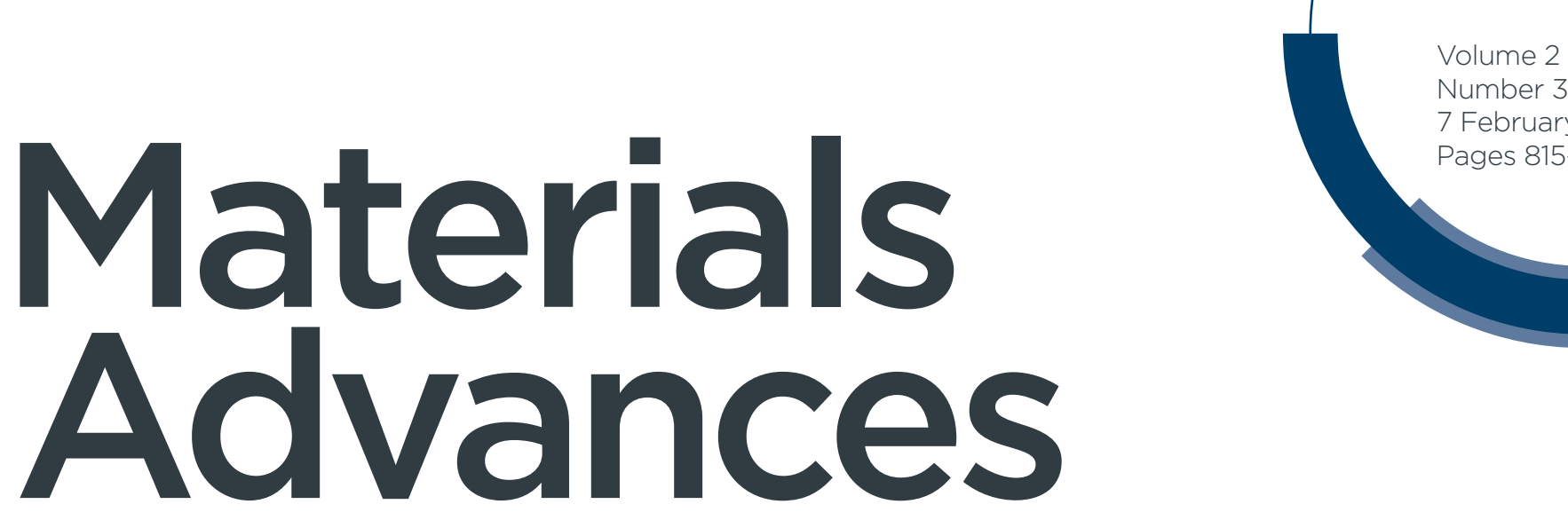

Number 3

7 February 2021

Pages 815-1100

rsc.li/materials-advances

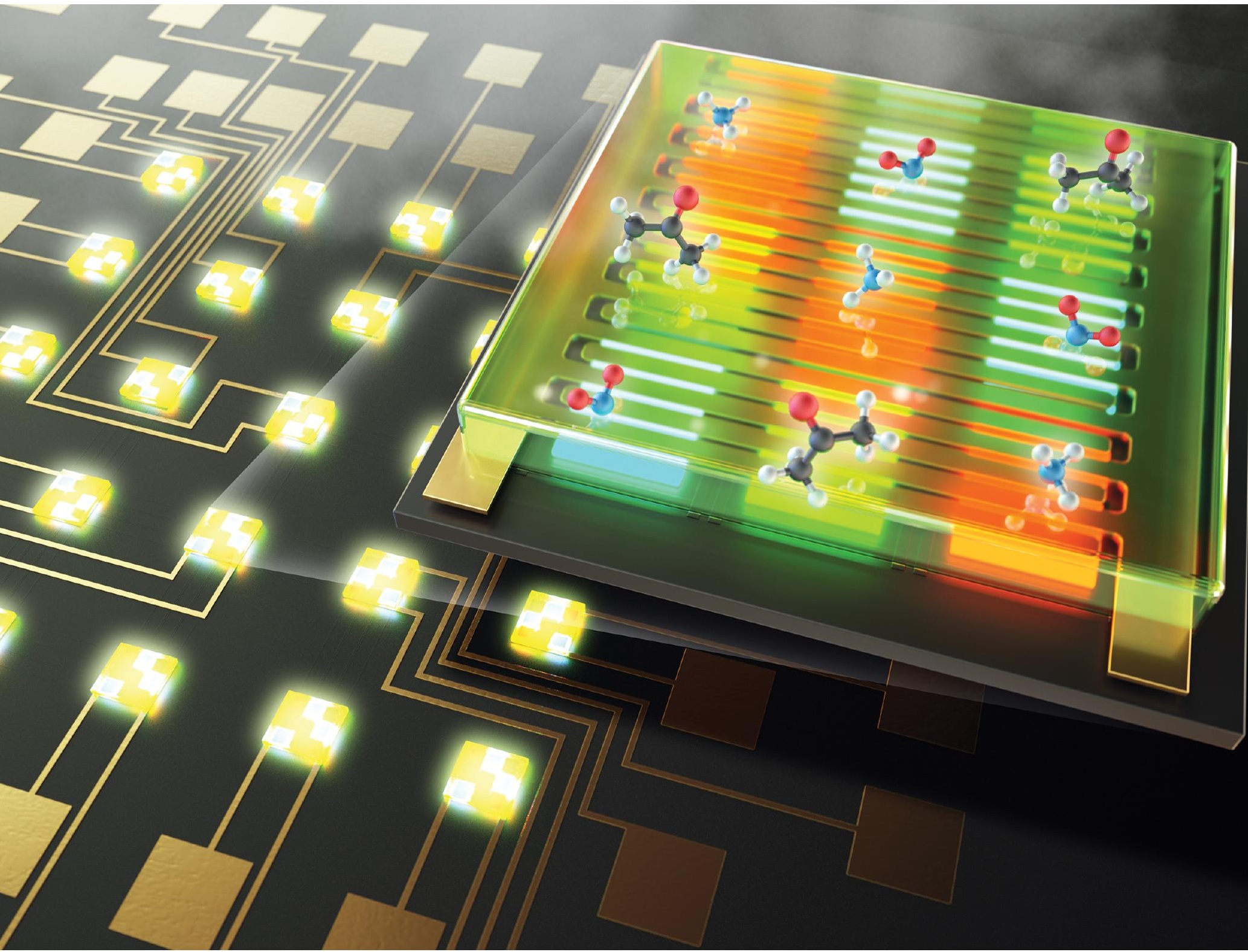

ISSN 2633-5409

ROYAL SOCIETY OF CHEMISTRY

\section{REVIEW ARTICLE}

Jun Min Suh, Ho Won Jang et al.

Light-activated gas sensing: a perspective of integration

with micro-LEDs and plasmonic nanoparticles 
Check for updates

Cite this: Mater. Adv., 2021, 2, 827

Received 7th September 2020, Accepted 30th November 2020 DOI: 10.1039/d0ma00685h

rsc.li/materials-advances

\title{
Light-activated gas sensing: a perspective of integration with micro-LEDs and plasmonic nanoparticles
}

\author{
Jun Min Suh, (D) *† Tae Hoon Eom, $\dagger$ Sung Hwan Cho, $\uparrow$ Taehoon Kim and \\ Ho Won Jang (D) *
}

\begin{abstract}
Light-activated gas sensors have been investigated for their superior potential to replace current thermally activated gas sensors, which have several drawbacks for the Internet of Everything application. This review summarizes the various efforts made for the development of light-activated gas sensors and provides an overview of their progress. The light-activated gas sensing properties of metal oxides, 2D materials, and other candidate materials are summarized. As strategies to overcome the current challenges of light-activated gas sensors, the effects of nanostructures and crystallographic orientations are discussed. Finally, the incorporation of plasmonic nanoparticles and integration with micro lightemitting diodes are proposed for the pathway toward the real application of light-activated gas sensors. This review should offer a broad range of readers a new perspective toward the future development of

light-activated gas sensors.
\end{abstract}

\section{Introduction}

With the emerging Internet of Everything (IoE) era, the significance of sensor technologies has been emphasized and led to a dramatic development in sensor technologies during the last decade. ${ }^{1}$ With the IoE platform, the inter-connections between various sensors and mobile devices can collect numerous

Department of Materials Science and Engineering, Research Institute of Advanced Materials, Seoul National University, Seoul 08826, Republic of Korea.

E-mail: hwjang@snu.ac.kr

$\dagger$ These authors contributed equally to this work. helpful data from the surrounding environments and process them into useful information for modern human life. These various sensors can be classified into five groups depending on the five human senses: vision for the image sensor, touch for a pressure sensor, hearing for voice recognition, taste for an electronic tongue, and smell for gas sensors. The gas sensors in IoE applications are required to have a small size with low power consumption for their embedding in portable devices, not to mention excellent gas sensing performance. ${ }^{2}$

To achieve the requirements for IoE application, various gas sensor principles have been suggested including cantilever-based

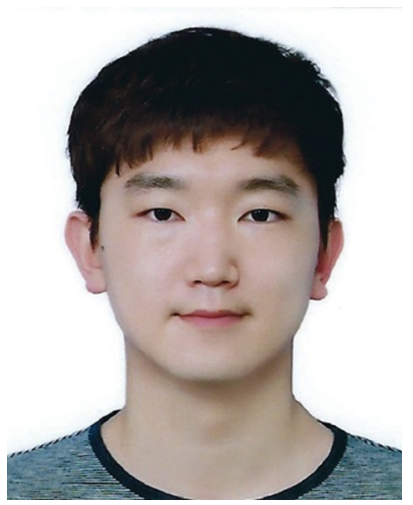

Jun Min Suh
Jun Min Suh is Postdoctoral Associate at Research Institute of Advanced Materials, Department of Materials Science and Engineering, Seoul National University. He earned his PhD from the Department of Materials Science and Engineering, Seoul National University in August, 2020. His research focuses on nanostructured electronic materials including metal oxides and $2 D$ materials for gas sensor applications.

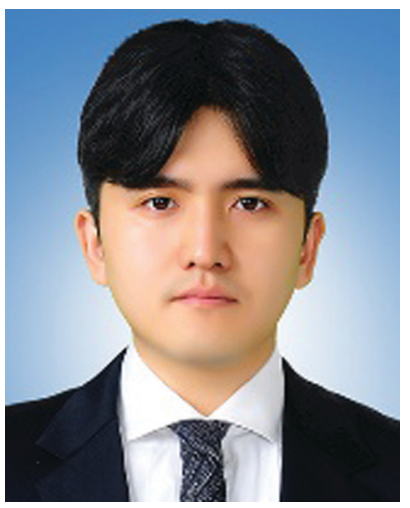

Tae Hoon Eom is a PhD candidate in the Department of Materials Science and Engineering in Seoul National University. His research focuses on the synthesis of $2 D$ materials and their applications in light-activated roomtemperature gas sensors.
Tae Hoon Eom 
gas sensors, ${ }^{3}$ capacitive gas sensors, ${ }^{4}$ thermometric gas sensors, ${ }^{5}$ optical gas sensors, ${ }^{6}$ field-effect transistor gas sensors, ${ }^{7}$ colorimetric gas sensors, ${ }^{8}$ solid-state electrochemical gas sensors, ${ }^{9,10}$ or chemoresistive gas sensors. ${ }^{11-13}$ Among them, the chemoresistive gas sensors have been considered the most appropriate due to their simple structure with easy fabrication processes and low cost. These advantages can result in small size and compatibility with the existing electrical circuits, suitable for the IoE application. Their working principles are based on the resistance change upon adsorption and desorption of target gas molecules on the surface of semiconductors.

The chemoresistive gas sensors usually utilize various semiconducting materials including metal oxides, ${ }^{14-22}$ 2-dimensional (2D) materials, ${ }^{23-30}$ or conductive polymers. ${ }^{31-33}$ Although each material has been reported for its superior gas sensing characteristics to specific target gas molecules through various strategies, a common challenge exists, which is the high operating temperature. Metal oxides require operating temperatures around $250-350{ }^{\circ} \mathrm{C}$ for the activation of the interaction with gas molecules. ${ }^{34}$ Two-dimensional materials and conductive polymers are usually capable of operating at low temperatures near the room temperature, but some amount of heat should be provided to overcome their slow kinetics in the aspect of practical applications. Therefore, heaters have been irreplaceable components in gas sensors, but they induce thermal degradation of the nearby electronic components during operation, causing limitation in the miniaturization and low reliability of sensor systems, which is the primary reason for high-power consumption. ${ }^{35}$

As an alternative to heaters, the light source, in particular light-emitting diodes (LEDs), has been one of the great candidates for the activation of semiconductors or gas-sensing materials at low temperatures. ${ }^{36,37}$ The appropriate choice of light wavelength with a higher energy than the bandgap energy of semiconductors can excite internal charge carriers to participate in chemical reactions with gas molecules. However, further modifications to the materials are needed other than just relying on bulk material properties to further utilize light energy and satisfy the IoE requirements. Therefore, there have been numerous efforts reported with various strategies including (i) utilization of plasmonic nanoparticles, ${ }^{38,39}$ (ii) utilization of other new materials, ${ }^{40-42}$ (iii) designing effective nanostructures, ${ }^{43,44}$ or (iv) integration with micro-LEDs. ${ }^{45}$

In this review, we summarize all the efforts made to improve light-activated gas sensors to exhibit promising enough gas sensing performance to be utilized in the IoE application with extremely low power consumption. To the best of author's knowledge, there has been no systematic review on the lightactivated gas sensors based on various electronic materials including metal oxides, 2D materials, or inorganic halide perovskites. ${ }^{36,37}$ This review is believed to provide a future insight into the development of low-power consuming gas sensors through promising light activation. Particularly, we want to highlight the utilization of plasmonic nanoparticles and integration with micro-LEDs in a future perspective of light-activated gas sensors, considering their extraordinary light-absorbing characteristics.

\section{Principles of light-activated gas sensors}

The first suggestion of light-activated gas sensing can probably be dated back to 1957 when D. A. Melnick reported the oxygen adsorption process on the surface of $\mathrm{ZnO}$ in relation to $\mathrm{ZnO}$ photoconduction. ${ }^{46}$ Although this study on oxygen adsorption had not been applied to any practical gas sensors, D. A. Melnick revealed the role of chemisorbed oxygen atoms as trap sites for

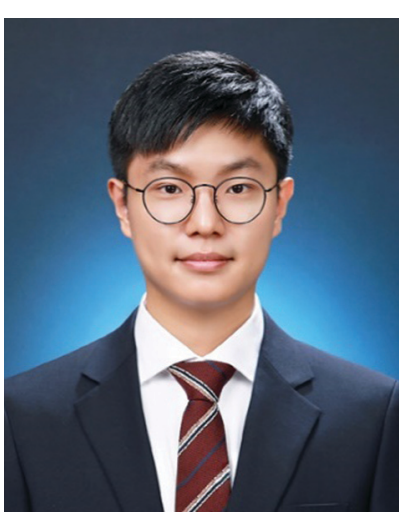

Sung Hwan Cho is a PhD candidate in the Department of Materials Science and Engineering in Seoul National University. His research focuses on room-temperature colorimetric gas sensors and metal oxide-based gas sensors.

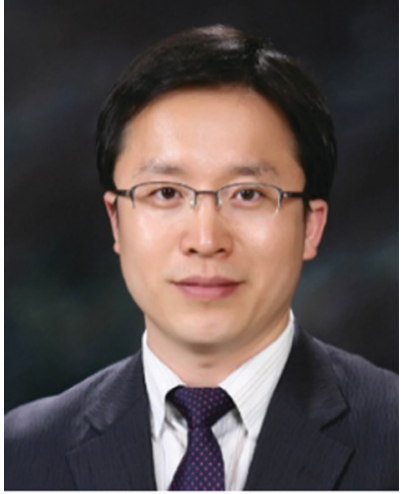

Ho Won Jang
Ho Won Jang is an Associate Professor in the Department of Materials Science and Engineering in Seoul National University. He earned his PhD from the Department of Materials Science and Engineering in Pohang University of Science and Technology in 2004. He worked as a Research Associate at the University of Wisconsin-Madison from 2006 to 2009. Before he joined Seoul National University in 2012, he worked in Korea Institute of Science and Technology as a Senior Research Scientist. His research interests include the synthesis of oxides, $2 D$ materials, and halide perovskites, and their applications in nanoelectronics, solar water splitting cells, chemical sensors, plasmonics, metal-insulator transition, and ferroelectricity. 
conduction electrons induced by $\mathrm{ZnO}$ photo-excitation. Since then, until the 1990s, when J. T. Cheung got patent for ambienttemperature gas sensors that utilized light irradiation for the stimulation of photodesorption of the gas from the surface of the film, most of the gas sensor research had been focused on operation at high temperatures. ${ }^{47}$ Performance-wise, the high operating temperature certainly secured fast kinetics with superior gas responses toward various gases. However, with the increase in demands for highly mobile devices with various functionalities, extensive research on gas sensors has started to focus on reducing power consumption by lowering the operating temperatures. As mentioned before, the adoption of light sources as activation sources has been one of the most notable strategies to achieve low power consumption and as illustrated in Fig. 1a, various candidate materials can be utilized to develop high-performance gas sensors at low temperatures. From the Web of Science literature survey from 2011 to July 2020 , the number of studies about gas sensors operating at low temperatures has been trending up and the number of studies about light-activated gas sensors has also been increasing dramatically (Fig. 1b and c). These trends well support the significance of light activation as a promising strategy to develop low-power consuming gas sensors.

The most widely accepted mechanism for the chemoresistive gas sensors is the oxygen absorbate-mediated electric interaction. ${ }^{48}$ The oxygen molecules get adsorbed onto the surface of semiconductors in three ionized states $\mathrm{O}_{2}{ }^{-}, \mathrm{O}^{-}$, or $\left.\mathrm{O}^{2-}\right)$ depending on the operating temperature. ${ }^{49}$ According to N. Barsan and U. Weimar, the molecular form $\left(\mathrm{O}_{2}{ }^{-}\right)$dominates

(a)
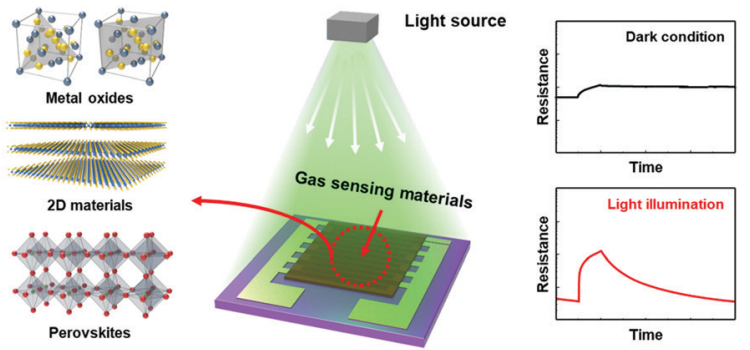

(b)

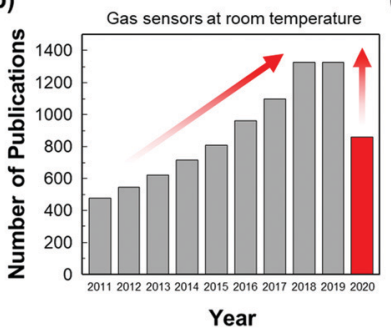

(c)

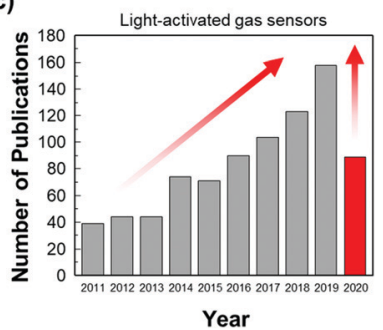

Fig. 1 (a) Schematic of the light-activated gas sensor. Results from a Web of Science literature survey for articles about (b) gas sensors operating at low temperatures and (c) light-activated gas sensors from 2011 to July, 2020. Web of Science [v.5.35] Core Collection Search keywords: (b) TS = gas sensor AND (TS = room temperature OR TS = low temperature) and (c) TS = gas sensor AND (TS = room temperature OR TS = low temperature) $\mathrm{AND}(\mathrm{TI}=\mathrm{UV} \mathrm{OR} \mathrm{TI}=$ ultraviolet $\mathrm{OR} \mathrm{TI}=$ light $\mathrm{OR} \mathrm{TI}=$ illumination $\mathrm{OR}$ $\mathrm{TI}=\mathrm{LED} O \mathrm{OR} \mathrm{TI}=$ photo OR $\mathrm{TI}=$ irradiation). ionosorption at a temperature below $150{ }^{\circ} \mathrm{C}$ and the atomic form $\left(\mathrm{O}^{-}\right.$or $\left.\mathrm{O}^{2-}\right)$ dominates at a temperature over $150{ }^{\circ} \mathrm{C} .{ }^{34}$ Although oxygen molecules $\left(\mathrm{O}_{2 \text { (gas) }}\right)$ have a very low chance of ionosorption at room temperature, several studies have experimentally confirmed the ionized oxygen molecules $\left(\mathrm{O}_{2(\mathrm{ads})}{ }^{-}\right)$ on the surface of semiconductors at room temperature. B. Liu et al. and L. Liu et al. measured the conductivity of the semiconductors under either pure $\mathrm{O}_{2}$ and pure $\mathrm{N}_{2}$ without any external heating or photo-activation, indicating ionosorption of $\mathrm{O}_{2} \cdot{ }^{50,51}$ Therefore, the light-activated gas sensors operating at room temperature are also expected to have oxygen absorbate-mediated gas sensing mechanisms, and most of the previously reported papers also interpret their gas sensing properties through oxygen absorbates. Fig. 2 summarizes the oxygen adsorption process under dark and light irradiated conditions. Under the dark conditions, the oxygen adsorption follows the conventional mechanism that molecular oxygen $\left(\mathrm{O}_{2(\text { ads })}{ }^{-}\right)$adsorbs onto the surface. Under light irradiation, photogeneration of electrons and holes takes place. The photogenerated holes $\left(\mathrm{h}_{(\mathrm{photo})}{ }^{+}\right)$interact with adsorbed molecular oxygen $\left(\mathrm{O}_{2(\mathrm{ads})}{ }^{-}\right)$to desorb them from the surface $\left(\mathrm{h}^{\text {(photo)+ }}+\mathrm{O}_{2 \text { (ads) }}{ }^{-} \leftrightarrow \mathrm{O}_{2(\text { gas })}\right)$. The exposed reactive sites after desorption of oxygen can be considered advantageous to gas sensing reactions due to an increased number of reactive sites. ${ }^{52}$ The released oxygen and the pre-existed oxygen react again with photogenerated electrons $\left(\mathrm{e}_{(\text {photo })}{ }^{-}\right)$to adsorb molecular oxygen again $\left(\mathrm{O}_{2 \text { (gas) }}+\mathrm{e}_{(\text {photo })}{ }^{-} \leftrightarrow\right.$ $\left.\mathrm{O}_{2 \text { (photo) }}{ }^{-}\right)$. The photo-adsorbed oxygen molecules $\left(\mathrm{O}_{2 \text { (photo) }}{ }^{-}\right)$ are expected to weakly bound to semiconductors and be more reactive than naturally ionosorbed oxygen molecules $\left(\mathrm{O}_{2(\mathrm{ads})}{ }^{-}\right)$, which are thermodynamically stable and less reactive at room temperature. ${ }^{53}$ Therefore, overall gas sensing kinetics and gas responses can be accelerated under light irradiation. The photo-adsorbed oxygen molecules then react with target gas molecules. For example, $\mathrm{NO}_{2}$, the most notable oxidizing gas, takes electrons away from photo-adsorbed oxygen to increase the resistance in the case of n-type semi-

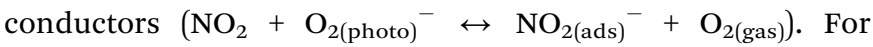
reducing gases like $\mathrm{CH}_{3} \mathrm{COCH}_{3}$, electrons are transferred from reducing gases to semiconductors with products of $\mathrm{CO}_{2}$ and $\mathrm{H}_{2} \mathrm{O}\left(\mathrm{CH}_{3} \mathrm{COCH}_{3}+4 \mathrm{O}_{2 \text { (photo) }}{ }^{-} \leftrightarrow 3 \mathrm{CO}_{2}+3 \mathrm{H}_{2} \mathrm{O}+4 \mathrm{e}^{-}\right)$, resulting in a decrease in the resistance in the case of n-type semiconductors.
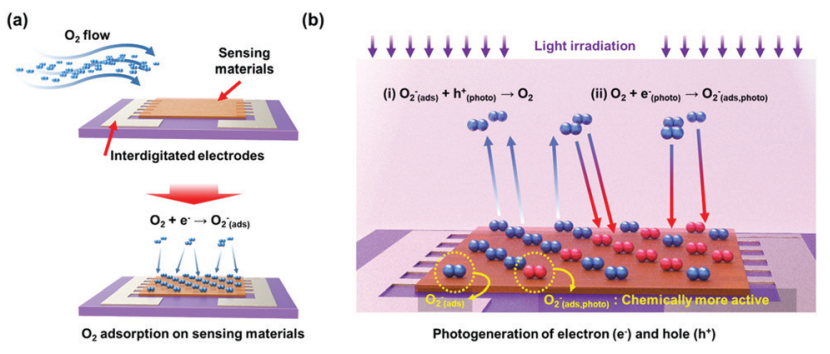

Fig. 2 Schematic of the oxygen adsorption process under (a) dark condition and (b) light irradiated conditions. 


\section{Light-activated gas sensing properties of semiconductors}

\subsection{Metal oxides}

The metal oxide semiconductors, such as $\mathrm{SnO}_{2}, \mathrm{WO}_{3}, \mathrm{ZnO}, \mathrm{NiO}$, $\mathrm{Co}_{3} \mathrm{O}_{4}$, or $\mathrm{In}_{2} \mathrm{O}_{3}$ have been one of the most widely adopted gas sensing materials. ${ }^{54-59}$ The current commercially available gas sensors are mostly based on metal oxide semiconductors due to their earth-abundant availability and cheap price. ${ }^{60}$ The metal oxide semiconductors also have strength in the detection of various volatile organic compounds (VOCs) at a low concentration, which is essential for indoor air monitoring. ${ }^{48,61}$ However, as mentioned before, their high operating temperature over $250{ }^{\circ} \mathrm{C}$ has been the most significant hurdle to be applied to mobile devices due to high power consumption. Although some companies have been successful in reducing power consumption through pulsed voltage application, it is still not enough to fulfil the requirements for IoE applications. ${ }^{62}$ Therefore, alternative methods like light activation have been highly demanded.

In the aspect of the light activation, most of the metal oxide semiconductors have bandgap energies higher than $3.0 \mathrm{eV}$, which is in the ultraviolet (UV) range. ${ }^{63}$ Therefore, most of the light-activated gas sensors based on metal oxides utilize UV light as an activation source. B. Liu et al. reported the UV lightactivated gas sensing properties of $\mathrm{SnO}_{2}$ nanosphere array films. ${ }^{50}$ Fig. 3a shows a cross-sectional scanning electron microscopic (SEM) image of the fabricated $\mathrm{SnO}_{2}$ nanospheres. As shown in Fig. 3b, the authors illuminated UV light to a monolayer of $\mathrm{SnO}_{2}$ nanospheres with different light intensities to find the optimal intensity, while $10 \mathrm{ppm} \mathrm{NO}_{2}$ was injected into the chamber. The optimal intensity was $3.09 \mathrm{~mW} \mathrm{~cm}$ and the gas sensing response was significantly enhanced compared to that under dark conditions. Under the illumination of the optimized UV light intensity, the $\mathrm{SnO}_{2}$ nanosphere with a different number of layers has been prepared and exposed to different concentrations of $\mathrm{NO}_{2}$ (Fig. 3c-f). All the sensors exhibited a perfect linear relationship to the target gas. The gas responses and sensitivity (the slope of the graph in response to concentration relationship) were all highest for the $\mathrm{SnO}_{2}$ nanospheres with 4 layers under UV light illumination. Under the same intensity of light illumination, the top layers absorb most of the illuminated light and the bottom region absorbs a little of it. Therefore, the $\mathrm{SnO}_{2}$ nanospheres with 6 layers were too thick to utilize UV light illumination for gas sensing reactions and 4 layers were the optimal thickness for the reaction. The optimized $\mathrm{SnO}_{2}$ nanosphere with 4 layers exhibited $\mathrm{NO}_{2}$ selectivity, which is expected to have benefited from excessive photogenerated electrons for the reduction of $\mathrm{NO}_{2}$, which consumes electrons unlike reducing gases.

X.-X. Wang et al. approached in a way more practical point of view and utilized a polychromatic (white) light source as an activation source. ${ }^{64}$ The authors fabricated the array of wellaligned $\operatorname{In}_{2} \mathrm{O}_{3}$ nanowires on polyimide substrates to achieve flexible and transparent sensors. Fig. 4a-d shows the schematic of the fabricated sensors with optical photographs and SEM (a)

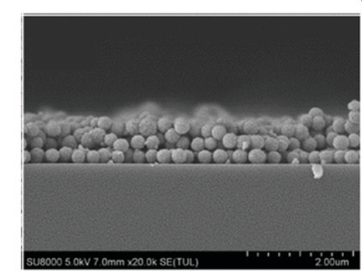

(c)

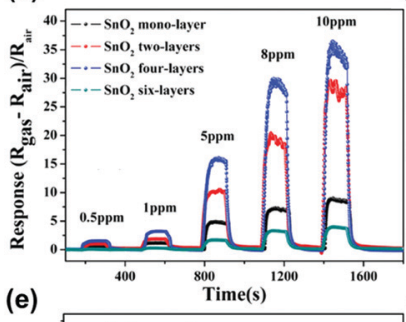

(b)
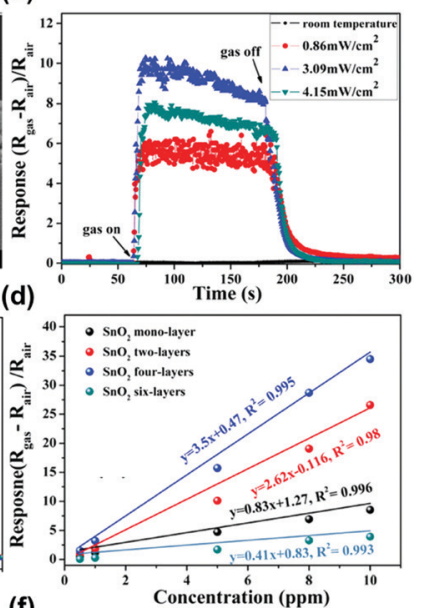

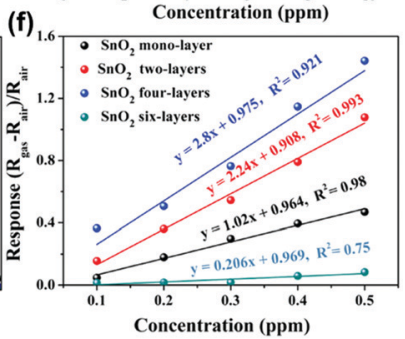

Fig. 3 (a) Cross-sectional scanning electron microscopic (SEM) images of the $\mathrm{SnO}_{2}$ array film with tri-layers. (b) Optimum irradiation intensity gas measurement of $\mathrm{SnO}_{2}$ monolayer array film toward $10 \mathrm{ppm} \mathrm{NO}$. The gas response comparison based on the $\mathrm{SnO}_{2}$ film with different thicknesses toward $\mathrm{NO}_{2}$ in the concentration range of (c) $0.5-10 \mathrm{ppm}$ and (d) the corresponding linear relationships. (e) The same measurements for $\mathrm{NO}_{2}$ concentration range of $100-500 \mathrm{ppb}$ and (f) the corresponding linear relationships. Reproduced with permission from ref. 50. Copyright (C) 2019 John Wiley \& Sons.

images. The fabricated gas sensors based on the $\operatorname{In}_{2} \mathrm{O}_{3}$ nanowire array were exposed to $500 \mathrm{ppb} \mathrm{NO}_{2}$ under different light sources at room temperature, as shown in Fig. 4e. Interestingly, the sensors exhibited responses to $500 \mathrm{ppb} \mathrm{NO}_{2}$ under all illuminated light wavelengths including white, blue, green, and red. While gas measurement under green and red light exhibited recovery characteristics and notable gas responses, their response or recovery times were relatively long. In addition, their base resistance in the $\mathrm{G} \Omega$ range can limit their future practical application due to noisy current. Therefore, the monochromatic blue light and polychromatic white light were chosen for further characterization. The $\operatorname{In}_{2} \mathrm{O}_{3}$ gas sensors were then exposed to $\mathrm{NO}_{2}$ of different concentrations under blue light, as shown in Fig. 4f, and their gas responses were plotted as a function of $\mathrm{NO}_{2}$ concentration, as shown in Fig. 4g. The gas response and $\mathrm{NO}_{2}$ concentration exhibited excellent linear relationships, indicating the capability of sensor calibration. The stable operation under blue light irradiation toward $500 \mathrm{ppb} \mathrm{NO}_{2}$ was also confirmed, as shown in Fig. $4 \mathrm{~h}$. The same measurements were conducted under white light, as shown in Fig. $4 \mathrm{i}-\mathrm{k}$, and they also exhibited a good linear relationship with long-term stability. Then the authors conducted gas sensing measurement under polychromatic light originating from iPhone screen illumination. 

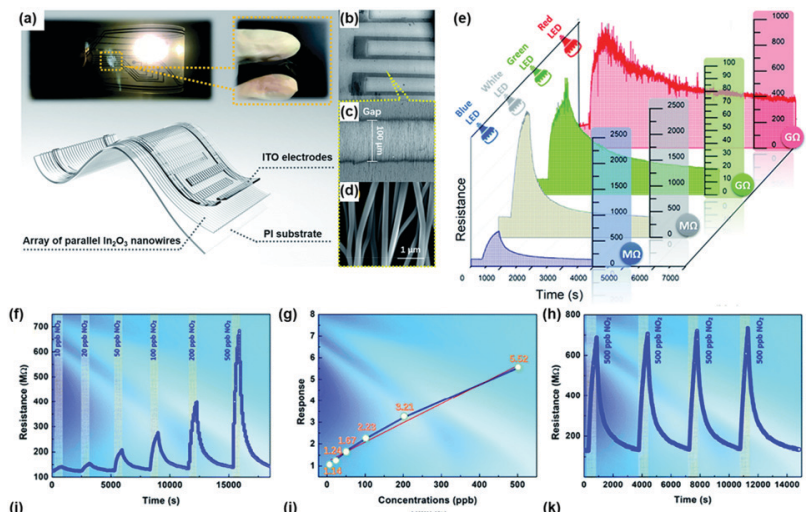

(i)
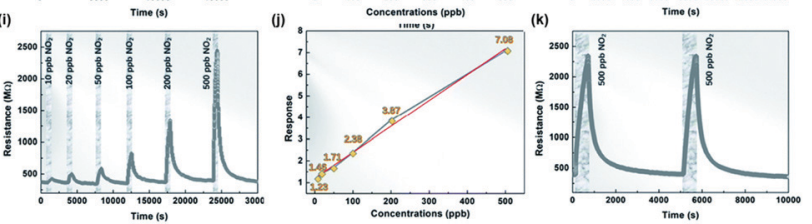

Fig. $4(a-d)$ Photographs and schematic of flexible and transparent sensors based on an array of parallel $\mathrm{In}_{2} \mathrm{O}_{3}$ nanowires: (a) transparent sensor pasted on a bookmark light (with a white LED, 1 W; powered by a $3 \mathrm{~V}$ button battery), (b) SEM images of the flexible and transparent sensors based on the $\ln _{2} \mathrm{O}_{3}$ nanowire array under low magnification, (c) wellaligned nanowires across the electrodes, and (d) parallel $\ln _{2} \mathrm{O}_{3}$ nanowires under high magnification. (e) Response of the sensor based on the $\ln _{2} \mathrm{O}_{3}$ nanowire array to $500 \mathrm{ppb} \mathrm{N_{2 }}$ under illumination using different light sources at room temperature. $(\mathrm{f}-\mathrm{k})$ Gas sensing properties of the sensor based on the $\mathrm{In}_{2} \mathrm{O}_{3}$ nanowire array at room temperature: (f) responserecovery curve of the sensor to different $\mathrm{NO}_{2}$ concentrations, (g) sensor response as a function of $\mathrm{NO}_{2}$ concentration, and (h) response-recovery curve of the sensor to cyclic $\mathrm{NO}_{2}$ exposure under blue LED illumination; (i) response-recovery curve of the sensor to different $\mathrm{NO}_{2}$ concentrations, (j) sensor response as a function of $\mathrm{NO}_{2}$ concentration, and (k) long-term stability (after 180 days and 1000 bendings) under white LED illumination. Reproduced with permission from ref. 64. Copyright (C) 2020 Royal Society of Chemistry.

The iPhone was placed under the chamber with an iPhone screen facing toward $\operatorname{In}_{2} \mathrm{O}_{3}$ gas sensors. The distance between sensors and iPhone was $10 \mathrm{~cm}$, and irradiance was measured to be $0.56 \mathrm{~W} \mathrm{~m}^{-2}$ when the iPhone screen brightness was set at $100 \%$, which is low compared to the white light source used in the measurement (Fig. 4i-k). The iPhone light-illuminated gas sensing toward $500 \mathrm{ppb} \mathrm{NO} \mathrm{N}_{2}$ exhibited reasonable gas responses and demonstrated potential application and integration of gas sensors with displays of mobile devices.

Although light illumination on metal oxides was effective in lowering operating temperatures, sensitive and selective detection of VOCs still remains challenging due to their low response even under light illumination. ${ }^{65-67}$ N. D. Chinh et al. studied gas sensing properties of $\operatorname{In}_{2} \mathrm{O}_{3}$ nanostructures under UV light illumination at room temperature. ${ }^{68}$ The measurement toward various gases also revealed highly sensitive behavior to $\mathrm{NO}_{2}$ like other reports while exhibiting low gas responses toward VOCs. According to authors, UV illumination is effective in the generation of charge carriers for photocatalytic enhancement of gas sensing characteristics; its effect on chemical reactions occurring on the surface is much smaller than the temperature effect. Especially, the chemical reaction of reducing gases $\left(\mathrm{C}_{2} \mathrm{H}_{5} \mathrm{OH}, \mathrm{CH}_{3} \mathrm{COCH}_{3}, \mathrm{HCHO}\right.$, or $\left.\mathrm{CH}_{4}\right)$, which has water molecules as a product, cannot overcome water formation energy through supplied energy from UV illumination. Through UV illumination, adsorption and desorption of gas molecules can be significantly promoted and selective detection of oxidizing gases like $\mathrm{NO}_{2}$ and $\mathrm{NO}$ can be effectively achieved. Therefore, for the selective detection of VOCs with light activation of metal oxides, other systematic strategy to amplify low gas responses toward VOCs is highly demanded.

R. Jaisutti et al. reported amorphous indium-gallium-zinc oxide (IGZO) as one of those strategies to overcome low selectivity toward VOCs. ${ }^{69}$ Compared to other polycrystalline metal oxides that need to have inevitable Schottky barriers at grain boundaries, amorphous metal oxides can avoid the formation of Schottky barriers and promote efficient charge transport in the gas sensing layers. Fig. 5a and b show the schematic of the fabrication process and a photograph of the final device of IGZO gas sensors prepared on indium-tin-oxide (ITO) interdigitated electrodes. Fig. 5c shows the optical transmittance spectra and the Tauc plot for the IGZO gas sensors.

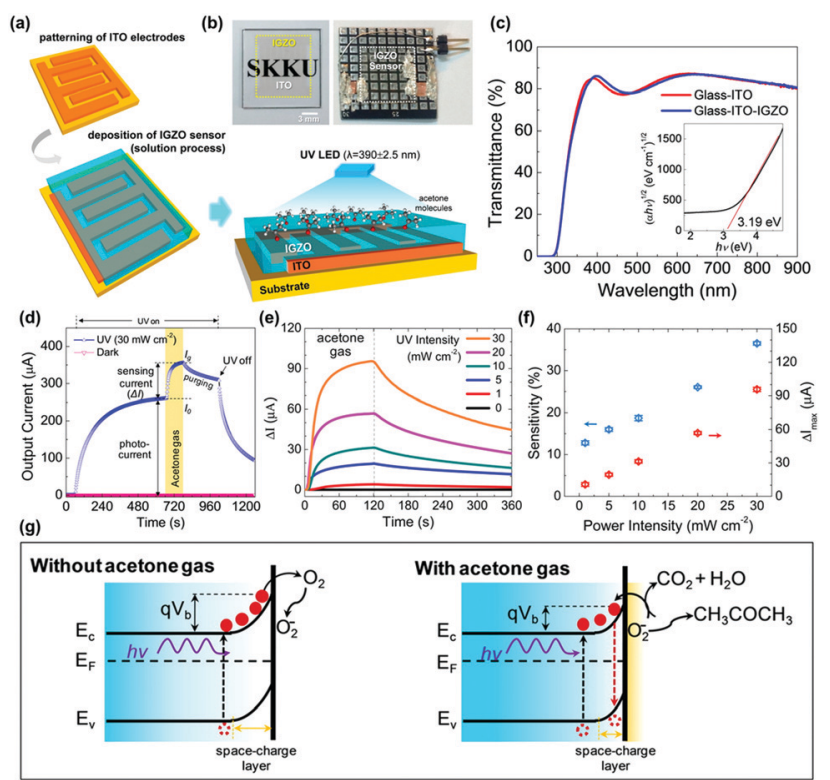

Fig. 5 (a) Schematic of the pattern of ITO interdigitated electrodes, solution processing of the IGZO film on the electrodes, and sensing operation under UV-LED irradiation and $\mathrm{CH}_{3} \mathrm{COCH}_{3}$ exposure. (b) Optical images of a transparent IGZO sensor before and after bonding on a print circuit board. (c) Optical transmittance spectra (inset shows that the Tauc plot exhibited the band gap of the IGZO film). (d) Overall response current behavior ( $/$ vs. $t$ ) of an IGZO gas sensor operated under a UV intensity of $30 \mathrm{~mW} \mathrm{~cm}^{-2}$ and a $\mathrm{CH}_{3} \mathrm{COCH}_{3}$ concentration of $750 \mathrm{ppm}$. (e) Gas sensing properties of UV-activated IGZO gas sensors operated under different UV intensities (1 to $30 \mathrm{~mW} \mathrm{~cm}$, with a $\mathrm{CH}_{3} \mathrm{COCH}_{3}$ concentration fixed at 750 ppm). (f) Current change $(\Delta /)$ and gas sensitivity during $\mathrm{CH}_{3} \mathrm{COCH}_{3}$ exposure at different UV intensities. (g) Schematic showing the energy band bending under photoinduced oxygen ions without (left) and with (right) interaction of $\mathrm{CH}_{3} \mathrm{COCH}_{3}$ molecules at the IGZO surface. Reproduced with permission from ref. 69. Copyright (C) 2016 American Chemical Society. 
The bandgap energy was calculated to be $3.19 \mathrm{eV}$, and this large bandgap contributed to high optical transmittance of the IGZO gas sensors. Fig. 5d shows the overall response current behavior of IGZO gas sensors toward UV illumination and acetone exposure. Under the dark condition, IGZO gas sensors did not exhibit any gas response toward $750 \mathrm{ppm} \mathrm{CH}_{3} \mathrm{COCH}_{3}$ due to the low electric conductivity of the IGZO and insufficient energy to overcome the activation energy of ionosorbed oxygen species. ${ }^{70}$ Under UV illumination, photogenerated electron and hole pairs increased the conductivity of the IGZO film, and photocurrent was significantly enhanced, as shown in Fig. 5d. In addition, as mentioned before, photogenerated electron and hole pairs participate in photocatalytic adsorption of oxygen as loosely bound active sites, and this induced saturation curves before exposure to $\mathrm{CH}_{3} \mathrm{COCH}_{3}$. Upon exposure to $\mathrm{CH}_{3} \mathrm{COCH}_{3}$, photocatalytically adsorbed oxygen species participate in the chemical reaction $\left(\mathrm{CH}_{3} \mathrm{COCH}_{3}+4 \mathrm{O}_{2 \text { (photo) }}{ }^{-} \leftrightarrow 3 \mathrm{CO}_{2}+3 \mathrm{H}_{2} \mathrm{O}\right.$ $+4 \mathrm{e}^{-}$) to release additional electrons to increase the conductivity of IGZO film. The IGZO gas sensors were then exposed to $750 \mathrm{ppm} \mathrm{CH}_{3} \mathrm{COCH}_{3}$ under UV light with different intensities ( 1 to $30 \mathrm{~mW}$ ), as shown in Fig. 5e. With the increase in UV intensities, the increased number of photogenerated electron and hole pairs can participate in photocatalytic adsorption of oxygen species and those loosely bound oxygen absorbates can enhance the gas sensing response of IGZO gas sensors toward $\mathrm{CH}_{3} \mathrm{COCH}_{3}$. Compared to the polycrystalline metal oxide, the amorphous IGZO film was beneficial in the transport of photogenerated charge carriers and efficient photocatalytic adsorption was available. The sensitivity (defined as (output current change) $/($ initial current) $\times 100 \%$ ) is summarized as a function of the UV power intensity, as shown in Fig. $5 \mathrm{f}$, and they exhibit a good linear relationship. The energy band bending according to the above-mentioned mechanisms is illustrated in Fig. 5g. The photogenerated electrons cause band bending at the surface and promote photocatalytic oxygen adsorption under ambient air. The IGZO gas sensors were exposed to various VOCs gases, including $\mathrm{CH}_{3} \mathrm{OH}, \mathrm{C}_{2} \mathrm{H}_{5} \mathrm{OH}, \mathrm{CH}_{3} \mathrm{CHOHCH}_{3}, \mathrm{CH}_{3} \mathrm{COCH}_{3}, \mathrm{C}_{7} \mathrm{H}_{8}$, and $\mathrm{C}_{6} \mathrm{H}_{5} \mathrm{Cl}$. As a result, the IGZO sensors exhibited sensitive behaviors to a group of alcohols $\left(\mathrm{CH}_{3} \mathrm{OH}\right.$ and $\left.\mathrm{C}_{2} \mathrm{H}_{5} \mathrm{OH}\right)$ and low sensitivity toward a group of organic solvents $\left(\mathrm{C}_{7} \mathrm{H}_{8}\right.$ and $\left.\mathrm{C}_{6} \mathrm{H}_{5} \mathrm{Cl}\right)$.

There have been other various strategies to overcome the low selectivity of metal oxide semiconductors under light illumination (mostly UV light) at room temperature, including formation of heterojunctions ${ }^{71-73}$ or catalyst decoration. ${ }^{74,75}$ Despite these efforts, the highest gas responses were usually exhibited when exposed to oxidizing gases like $\mathrm{NO}_{2}$ or $\mathrm{NO}$ and selective detection of VOCs remains challenging for the lightactivated gas sensors based on metal oxides. As N. D. Chinh et al. explained, not enough energy supplied by light illumination to overcome water formation energy, which is the product of VOCs sensing reaction, is the primary reason for the low VOC selectivity. ${ }^{68}$ As a result, the highly selective behavior only to oxidizing gases has been mainly reported by light-activated gas sensors based on metal oxides. The further strategies and efforts on the enhancement will be described in the later section of this review.

\subsection{Two-dimensional materials}

Two-dimensional materials including graphene, ${ }^{76}$ graphene derivatives, ${ }^{77-79}$ or transition metal dichalcogenides (TMDs) ${ }^{80,81}$ have been one of the most attracted materials for gas sensors operating at room temperatures. The $2 \mathrm{D}$ materials exhibit a high surface-to-volume ratio and a high surface energy, which are beneficial for adsorption and desorption of target gas molecules even at room temperature. While graphene and its derivatives are intrinsically metallic and have difficulties in opening a gap at the Dirac cone to limit their utilization of excellent electronic properties, TMDs including $\mathrm{MoS}_{2}, \mathrm{WS}_{2}$, and $\mathrm{SnS}_{2}$ are intrinsic semiconductors with distinct bandgaps for easy application to various electronic devices. ${ }^{82}$ In particular, in the aspect of light activation, TMDs with distinctive bandgap energies smaller than metal oxides can enable activation under visible light. Although a previously addressed work of X.-X. Wang et al. successfully demonstrated the light-activated gas sensing characteristics under the illumination of the iPhone screen, the light-activation heavily rely on a short wavelength region of polychromatic white light. ${ }^{63}$ If visible light can be used as an activation source, all the light sources available during human life can be used as activation sources, leading to more practically reasonable light-activated gas sensor technologies. The utilization of visible light sources can also prevent potential damages to sensing materials caused by UV light via generation of ozone in an oxygen-rich atmosphere. ${ }^{83}$

D. Gu et al. fabricated gas sensors based on $\mathrm{WS}_{2}$ microflakes for the detection of VOCs under light illumination with different wavelengths. ${ }^{84}$ Fig. 6a shows the SEM image of the prepared $\mathrm{WS}_{2}$ samples with a typical layered flake morphology. The microflake size varies from $1 \mu \mathrm{m}$ to $4 \mu \mathrm{m}$. Fig. $6 \mathrm{~b}$ shows the response curves of the $\mathrm{WS}_{2}$ microflakes under light illumination with different wavelengths $(365,525,580,850$, and $940 \mathrm{~nm})$ and dark conditions toward $10 \mathrm{ppm} \mathrm{NH}_{3}$. The operating temperature was $40{ }^{\circ} \mathrm{C}$ and the relative humidity condition was $30 \%$. Compared to the gas response under dark conditions, all light-illuminated gas responses exhibited higher values, indicating the capability of visible light absorption by prepared $\mathrm{WS}_{2}$ microflakes. Among various wavelengths, $365 \mathrm{~nm}$ light illumination exhibited the highest gas response with the fastest kinetics. The light illumination with longer wavelength exhibited slightly lower gas responses except for $940 \mathrm{~nm}$. A shorter wavelength with a higher energy will certainly be capable of excitation and photocatalytic oxidation at a higher rate than the longer wavelengths, corresponding to lower gas responses for longer wavelengths. The unexpectedly high gas response under $940 \mathrm{~nm}$ light illumination may be related to inconsistent light intensities for each light wavelength that authors did not mention in the manuscript, still these data show the capability of light activation of $\mathrm{WS}_{2}$ microflakes by visible light wavelength. Fig. $6 \mathrm{c}$ shows the resistance curves of the $\mathrm{WS}_{2}$ microflakes under light illumination with 365 and $940 \mathrm{~nm}$ and dark conditions toward 5-60 $\mathrm{ppm} \mathrm{NH}_{3}$. The responses toward different concentrations of $\mathrm{NH}_{3}$ are summarized as a function of $\mathrm{NH}_{3}$ concentration in Fig. 6d. These curves well support stable operation under visible light operation with excellent correlation curves, indicating the capability of sensor calibration. The gas sensing mechanism 
(a)

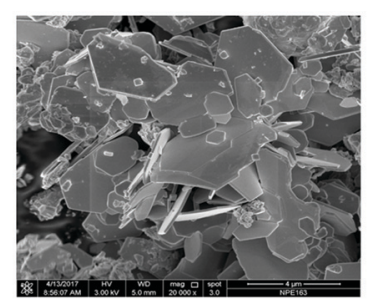

(c)

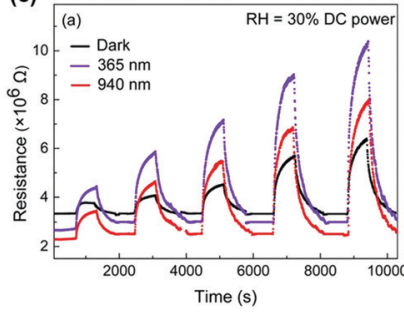

(b)

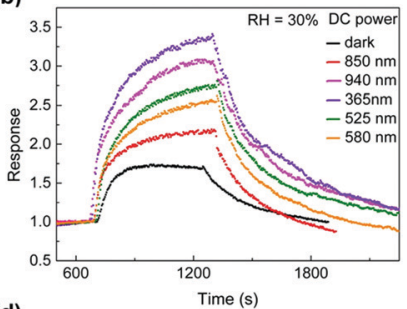

(d)

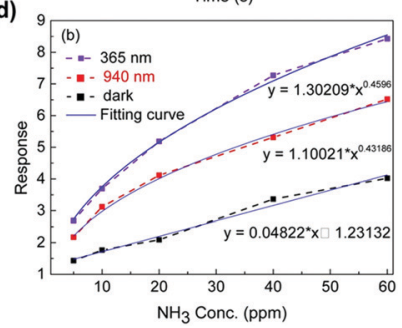

Fig. 6 (a) SEM images of the as-milled $W_{2}$ sample. (b) Response curves of the $\mathrm{WS}_{2}$-based chemoresistive sensors under different light illuminations driven by DC power to $10 \mathrm{ppm} \mathrm{NH}_{3}$. (c) Comparison of the resistance curve of the $W_{2}$-based sensor under light $(365 \mathrm{~nm}, 940 \mathrm{~nm}$ ) illumination driven by $\mathrm{DC}$ power and the darkness to $\mathrm{NH}_{3}$ from 5 to $60 \mathrm{ppm}$. (d) Correlation curve of the response of the sensor under the light (365 nm, $940 \mathrm{~nm}$ ) illumination and the darkness. Reproduced with permission from ref. 84. Copyright (C) 2017 Elsevier B. V.

follows that of metal oxides having photocatalytic oxygen adsorption and its high reactivity as primary contributing factors.

Another work by D. Gu et al. demonstrated visible lightactivated gas sensing characteristics of $\mathrm{SnS}_{2}$ nanosheets. ${ }^{85}$ Fig. 7a shows a SEM image of the prepared $\mathrm{SnS}_{2}$ nanosheets with typical layered structures with a size in the range of 50-200 nm. Fig. 7b shows the $I-V$ polarization curves of the $\mathrm{SnS}_{2}$ nanosheets under irradiation at different wavelengths. The $I-V$ characteristics of $\mathrm{SnS}_{2}$ nanosheets exhibit ohmic behaviors with a higher conductivity for the $\mathrm{SnS}_{2}$ nanosheets under light illumination at shorter wavelengths. Considering the widely reported bandgap of $\mathrm{SnS}_{2}(2.36 \mathrm{eV})$, the green wavelength corresponds to the bandgap energy, and the $I-V$ characteristic at a longer wavelength than the green wavelength exhibited relatively low conductivity, indicating less light activation. ${ }^{86,87}$ The fabricated $\mathrm{SnS}_{2}$-based gas sensors were exposed to 1-8 ppm $\mathrm{NO}_{2}$ under green light illumination at room temperature, and the gas response curves are shown in Fig. 7c. The gas response and gas concentrations exhibit a nearly linear relationship with stable operation and excellent recovery characteristics. Interestingly, the authors compared the gas selectivity of $\mathrm{SnS}_{2}$ nanosheets toward various gases under both green light illumination at room temperature and high operating temperature conditions without any light illumination (Fig. 7d). The overall gas selectivity under both activation modes (optical and thermal activations) exhibited almost the same selective behavior with similar gas responses. These results indicate that there was no significant influence on the choice of activation modes for the gas sensing characteristics of $\mathrm{SnS}_{2}$ nanosheets. Although limited selective behavior only to $\mathrm{NO}_{2}$ could not be improved even by adopting TMDs

(a)

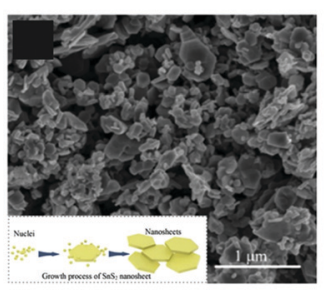

(b)

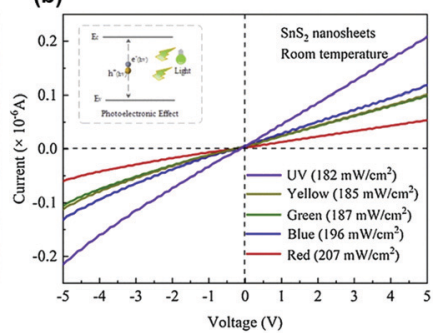

(c)

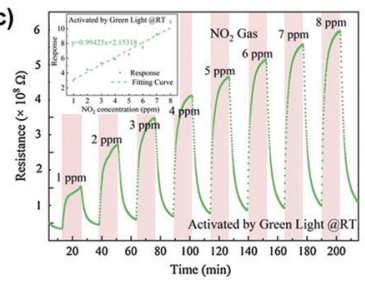

(d)

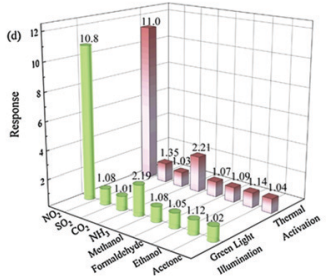

Fig. 7 (a) SEM image of the as-synthesized $\mathrm{SnS}_{2}$ nanosheets. (b) $1-V$ polarization curves of the $\mathrm{SnS}_{2}$-based sensor under different light sources. (c) Resistance of the as-fabricated $\mathrm{SnS}_{2}$-based sensor to 1-8 ppm $\mathrm{NO}_{2}$ concentrations and the correlation curve (inset) under green LED light activation at room temperature. (d) Selectivity of the sensor under two activation modes (green LED light and thermal activation) $\left(\mathrm{CO}_{2}: 30 \mathrm{ppm}\right.$; the other interferent gas: $10 \mathrm{ppm}$ ). Reproduced with permission from ref. 85. Copyright (C) 2020 Elsevier B. V.

as sensing channels for the light-activated gas sensors, nearly the same selective behavior under both optical and thermal activation modes implies selective distinguish between each VOC can be more capable by using TMDs than metal oxides under visible light illumination.

Y. Huang et al. reported $\mathrm{SnS}_{2} / \mathrm{rGO}$ nanohybrids with $\mathrm{p}-\mathrm{n}$ transition for the visible light-activated gas sensors. ${ }^{88}$ The heterojunction between two different $2 \mathrm{D}$ materials can exhibit light-activated gas sensing properties that cannot be expected from a single material. The authors controlled a ratio of rGO to manipulate the conduction type of $\mathrm{SnS}_{2} / \mathrm{rGO}$ nanohybrids to either n-type or p-type conduction through one-step hydrothermal methods. Fig. 8a shows the schematic illustration of the synthesis procedure of $\mathrm{SnS}_{2} / \mathrm{rGO}$ nanohybrids. $\mathrm{SnS}_{2}$ is an n-type semiconductor and the high composition ratio of rGO can result in p-type semiconducting characteristics. Fig. 8b-e shows the structural characterizations of n-type and p-type $\mathrm{SnS}_{2} /$ rGO nanohybrids. The rigid hexagonal $\mathrm{SnS}_{2}$ layers and lamellar structure of rGO can be confirmed through SEM images. The gas sensors were fabricated by drop-casting the synthesized $\mathrm{SnS}_{2} /$ rGO nanohybrids on interdigitated electrodes (IDEs) with patterned alumina substrates. Before light illumination, the gas sensing properties of $\mathrm{SnS}_{2}$ with varying rGO ratios were tested through exposure to $\mathrm{NO}_{2}$. Pure $\mathrm{SnS}_{2}$ exhibited almost no gas response to $\mathrm{NO}_{2}$ at room temperature, but the addition of $1 \mathrm{mg}$ rGO resulted in a significant increase in gas responses (255\%). This can be attributed to promoted charge transport from $\mathrm{SnS}_{2}$ to rGO through the $\mathrm{sp}^{2}$ orbital of rGO. After the addition of $5 \mathrm{mg} \mathrm{rGO}, \mathrm{SnS}_{2} / \mathrm{rGO}$ was converted from n-type into p-type conduction with a gas response of $47 \%$ toward 1 ppm $\mathrm{NO}_{2}$, and pure rGO exhibited almost negligible gas response toward $\mathrm{NO}_{2}$. 
(a)
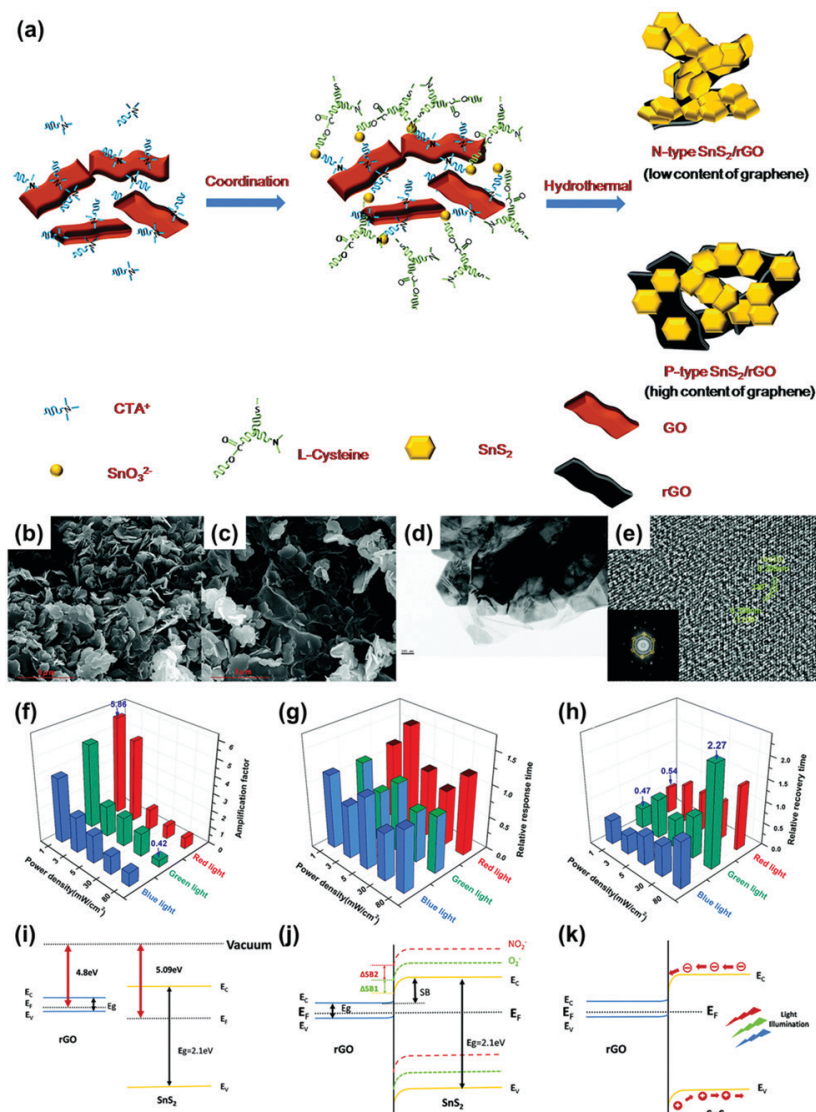

(g)
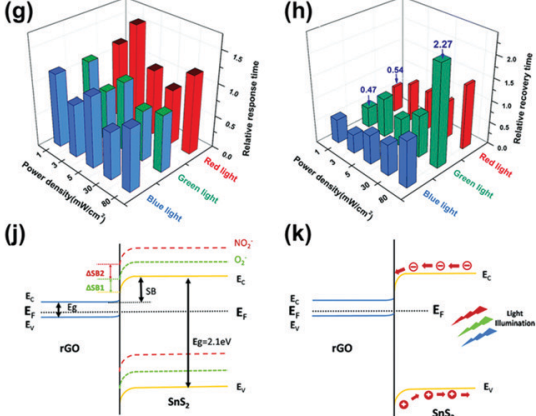

Fig. 8 (a) Schematic of the process of hydrothermal synthesis of $\mathrm{SnS}_{2} /$ $\mathrm{rGO}$ nanohybrids. SEM image of (b) $n$-type and (c) p-type $\mathrm{SnS}_{2} / \mathrm{rGO}$ nanohybrids. (d) TEM image of $\mathrm{SnS}_{2} / \mathrm{rGO}$ nanohybrids. (e) HRTEM image of $\mathrm{SnS}_{2}$ and the resulting FFT pattern (inset). (f-h) The effect of light illumination on the gas sensing properties of $n$-type $\mathrm{SnS}_{2} / \mathrm{rGO}$ sensors. (f) The amplification factor of sensitivity under light illumination of different wavelengths and power densities. (g) The relative response and (h) recovery times under light illumination of different wavelengths and power densities. (i-k) Proposed band alignment diagrams at the $\mathrm{SnS}_{2} / \mathrm{rGO}$ junctions. (i) Energy diagram of the $\mathrm{SnS}_{2}$ and $\mathrm{rGO}$ before forming hybrids. (j) Band realignment and energy diagram of $n$-type $\mathrm{SnS}_{2} / \mathrm{rGO}$ sensors and the formation of the Schottky barrier. Yellow, green and red lines indicate the energy band of the pristine $n$-type $\mathrm{SnS}_{2} / \mathrm{rGO}$ sensors (solid yellow), after exposure to $\mathrm{O}_{2}$ (dashed green) and after exposure to $\mathrm{NO}_{2}$ (dashed red), respectively. $\triangle \mathrm{SB} 1$ and $\triangle \mathrm{SB} 2$ represent the Schottky barrier shifted by the $\mathrm{O}_{2}$ and $\mathrm{NO}_{2}$, respectively. The light illumination will change the height of $\triangle$ SBland $\triangle \mathrm{SB} 2$ to affect the sensing behavior. ( $\mathrm{k}$ ) The band alignment diagram of the light-assisted $\mathrm{SnS}_{2} / \mathrm{rGO}$ sensors. Reproduced with permission from ref. 88 . Copyright (C) 2019 The Royal Society of Chemistry.

The heterojunctions between $\mathrm{SnS}_{2}$ and rGO facilitated gas sensing at room temperature even without light illumination. To investigate light-activated gas sensing characteristics of $\mathrm{SnS}_{2} / \mathrm{rGO}$ nanohybrids, blue (450 nm), green (532 nm), and red $(650 \mathrm{~nm})$ light illumination was conducted with varying intensities $(1,3,5,30$, and $80 \mathrm{~mW} \mathrm{~cm}^{-2}$ ) during exposure to $\mathrm{NO}_{2}$. The p-type $\mathrm{SnS}_{2} / \mathrm{rGO}$ nanohybrids exhibited almost no enhancement through light illumination since rGO is not a good photoelectric material and cannot provide sufficient photogenerated charge carriers due to the very small bandgap. However, n-type $\mathrm{SnS}_{2} / \mathrm{rGO}$ nanohybrids exhibited dramatically enhanced gas sensing characteristics upon light illumination. In Fig. 8f-h, the amplification factor (defined as (sensitivity at light)/(sensitivity at dark)), relative response time (defined as (response time at light)/(response time at dark)), and relative recovery time (defined as (recovery time at light)/(recovery time at dark)) of $\mathrm{SnS}_{2} / \mathrm{rGO}$ nanohybrids are summarized. Interestingly, the highest amplification factor was observed for the lowest light intensity. These results indicate that there is an optimal light intensity for the gas sensing reaction, which are in accordance with the previous reports on metal oxides and $\mathrm{MoS}_{2} \cdot{ }^{89-91}$ One of the possible reasons is that the number of photogenerated charge carriers that participate in the gas sensing reaction can decrease at an excessively high light intensity. Another possible reason is that the desorption reaction can dominate the adsorption reaction at an excessively high light intensity. The illuminated three wavelengths exhibited almost similar effects on gas sensing properties including gas responses as above, response times, and recovery times. The response time increased under all light illuminating conditions, while the recovery time was shortened at a low intensity and delayed at a high intensity. These can be attributed to direct photoexcitation of the electrons from $\mathrm{NO}_{2}$ into the conduction band, and intensity-dependent desorption processes. Fig. $8 \mathrm{i}-\mathrm{k}$ shows the proposed band alignment diagrams at the heterojunctions of $\mathrm{SnS}_{2} / \mathrm{rGO}$ nanohybrids regarding the descriptions above.

As explained, the 2D materials are capable of the activation under visible light illumination and prevention of possible damages that can be caused by UV light illumination. ${ }^{83}$ In addition, the utilization of visible light wavelength can provide more chance of practical application by taking advantage of numerous light sources available in everyday life. However, lacking selectivity toward VOCs still remains challenging as it was for metal oxides under light illumination at room temperature, and further studies are highly demanded to overcome it. ${ }^{92,93}$

\subsection{Other materials}

While metal oxides and 2D materials are the most widely studied electronic materials for the gas sensor application, there have been other efforts on discovering new possible electronic materials for the gas sensors including inorganic halide perovskites, ${ }^{40,41}$ metal sulfides, ${ }^{42,94-100}$ and organic semiconductors. ${ }^{53,101-103}$ This section summarizes the lightactivated gas sensing properties of electronic materials other than metal oxides and 2D materials.

A. Tricoli's group has first reported light-activated gas sensing properties of $\mathrm{CsPbBr}_{3}$ and $\mathrm{CsPbBr}_{2} \mathrm{I}$ inorganic halide perovskites. ${ }^{40,41}$ Unlike organic-inorganic hybrid perovskites suffering unstable operation and being stable under ambient air, inorganic halide perovskites which have Cs atoms as substitutes for organic cations can secure their stability to function as gas sensors. Fig. 9a shows the schematic of $\mathrm{O}_{2}$ sensing by $\mathrm{CsPbBr}_{3}$ based gas sensors. The cross-sectional SEM image in Fig. 9b indicates a $\mathrm{CsPbBr}_{3}$ film with $350 \mathrm{~nm}$ thickness deposited on a fluorine-doped tin oxide (FTO) glass. Upon exposure to the oxidizing gas of $\mathrm{O}_{2}$ at room temperature under the illumination of $420 \mathrm{~nm}$ visible light, highly sensitive detection of $\mathrm{O}_{2}$ was 

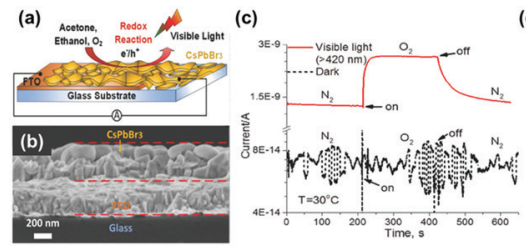

(d)
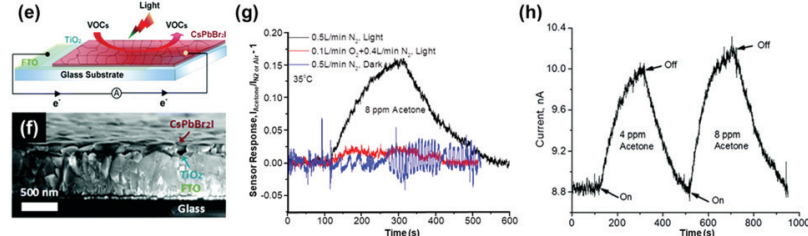

(i)

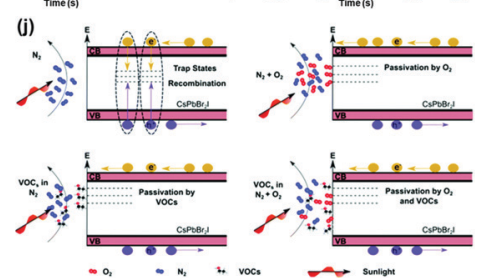

$-7.0 \mathrm{~F}$

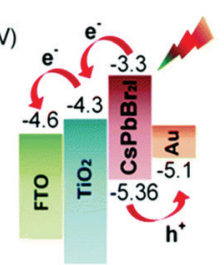

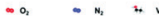

Fig. 9 (a) Schematic of $\mathrm{O}_{2}$ gas sensing by a $\mathrm{CsPbBr}_{3}$-based chemical sensor device. (b) Cross-sectional SEM image of an exemplary $\mathrm{CsPbBr}_{3}$ film deposited on an FTO glass substrate. (c) Dynamic responses of a typical $\mathrm{CsPbBr}_{3}$ sensor to switching the chemical environment from pure $\mathrm{N}_{2}$ to pure $\mathrm{O}_{2}$ in dark (broken line) and under visible-light illumination (red line). (d) Stability of the $\mathrm{CsPbBr}_{3}$ gas sensor response to the pure $\mathrm{N}_{2} / \mathrm{O}_{2}$ atmosphere switching under four consecutive cycles under visiblelight illumination. (e) Schematic of the $\mathrm{CsPbBr}_{2}$ l chemical sensor layout. (f) Cross-sectional SEM image of a representative $\mathrm{CsPbBr}_{2} \mid$ film deposited on a compact $\mathrm{TiO}_{2}$ layer on a FTO glass substrate. (g) Dynamic CsPbBr $\mathrm{Pb}_{2}$ sensor response to injection of $8 \mathrm{ppm} \mathrm{CH}_{3} \mathrm{COCH}_{3}$ in pure $\mathrm{N}_{2}$ (black line) and simulated air (red line) under simulated solar irradiation (AM 1.5, $42.3 \mathrm{~mW} \mathrm{~cm}^{-2}$ ), and in pure $\mathrm{N}_{2}$ under darkness (blue line). (h) Photocurrent response kinetics of a $\mathrm{CsPbBr}_{2} \mathrm{l}$ sensor to injection of 4 and $8 \mathrm{ppm}$ $\mathrm{CH}_{3} \mathrm{OCH}_{3}$ in pure $\mathrm{N}_{2}$. (i) Energy level diagram of the $\mathrm{CsPbBr}_{2} \mid$ device. (j) Schematic of the $\mathrm{CsPbBr}_{2}$ l chemical sensing mechanism. Reproduced with permission from ref. 40 and 41. Copyright (C) 2017 John Wiley \& Sons. Copyright (C) 2019 Royal Society of Chemistry.

available, as shown in Fig. 9c. Compared to the dynamic response of $\mathrm{CsPbBr}_{3}$ to $\mathrm{O}_{2}$ having almost no response, visible light illumination resulted in a gas response of 0.93 with extremely fast response time (17 s) and recovery time (127 s), which are difficult to achieve with other materials at room temperature. Fig. 9d shows the dynamic response curves of $\mathrm{CsPbBr}_{3}$ to four consecutive pulses of $\mathrm{O}_{2}$ under visible light illumination. The $\mathrm{CsPbBr}_{3}$ exhibited stable operation upon multiple exposures with consistent gas responses. Interestingly, when $\mathrm{CsPbBr}_{3}$ is exposed to reducing gases such as $\mathrm{C}_{2} \mathrm{H}_{5} \mathrm{OH}$ and $\mathrm{CH}_{3} \mathrm{COCH}_{3}$, the current level also increases as it does for oxidizing gases. This indicates that a somewhat different gas sensing mechanism takes place for $\mathrm{CsPbBr}_{3}$ compared to conventional semiconductors such as metal oxides and 2D materials. The authors emphasize that halide perovskites are ambipolar charge transporters due to the similarity of electron and hole effective mass. ${ }^{104,105}$ Based on the ambipolar properties of $\mathrm{CsPbBr}_{3}$, the authors propose that $\mathrm{O}_{2}$, $\mathrm{C}_{2} \mathrm{H}_{5} \mathrm{OH}$, and $\mathrm{CH}_{3} \mathrm{COCH}_{3}$ function as vacancy fillers and reversibly fill in intrinsic $\mathrm{Br}$ vacancies of the $\mathrm{CsPBr}_{3}$. Considering $\mathrm{Br}$ vacancies can trap the photogenerated charge carriers, the decreased number of $\mathrm{Br}$ vacancies after being filled in by the introduced target gas molecules results in an increase in the free photogenerated charge to increase the current level of $\mathrm{CsPbI}_{3}$. Fig. 9e shows the schematic of VOC sensing by $\mathrm{CsPbBr}_{2} \mathrm{I}$ under light illumination. $\mathrm{CsPbBr}_{2} \mathrm{I}$ has a broader absorption range than $\mathrm{CsPbBr}_{3}$, and therefore, it can be expected to exhibit different gas sensing characteristics from $\mathrm{CsPbr}_{3}$. Fig. 9f shows the crosssectional SEM image of the $\mathrm{CsPbBr}_{2} \mathrm{I}$ film deposited on the FTO glass. Upon exposure to $\mathrm{CH}_{3} \mathrm{COCH}_{3}$ gas at room temperature under solar irradiation ( $\mathrm{AM} 1.5,42.3 \mathrm{~mW} \mathrm{~cm}^{-2}$ ), $\mathrm{CsPbBr}_{2} \mathrm{I}$ exhibited highly sensitive detection of $\mathrm{CH}_{3} \mathrm{COCH}_{3}$, while there is almost no response under dark conditions, indicating that photogenerated charge carriers play a critical role in gas sensing (Fig. 9g). Fig. 9h shows the stable operation of $\mathrm{CsPbBr}_{2} \mathrm{I}$ toward two consecutive pulses of $\mathrm{CH}_{3} \mathrm{COCH}_{3}$ under light illumination. Similar to $\mathrm{CsPbBr}_{3}, \mathrm{CsPbBr}_{2} \mathrm{I}$ also exhibited a current increase upon exposure to both oxidizing gases and reducing gases, implying different gas sensing mechanisms from conventional semiconductors. Fig. 9i shows an energy band diagram of the $\mathrm{CsPbBr}_{3} \mathrm{I}$ gas sensors. Upon light illumination, photogenerated electrons transfer from the conduction band of $\mathrm{CsPbBr}_{2} \mathrm{I}$ to the FTO glass across the hole blocking layer, and the photogenerated holes transfer from the valence band of $\mathrm{CsPbBr}_{2} \mathrm{I}$ to the $\mathrm{Au}$ probe. ${ }^{106,107}$ As a result, the net current flow through the out circuit can be formed from the FTO glass to Au without any external ways. This current flow can be used to transduce the electrical characteristics upon exposure to target gas molecules. Fig. 9j illustrates the possible gas sensing mechanism of $\mathrm{CsPbBr}_{2} \mathrm{I}$ gas sensors. In a $\mathrm{N}_{2}$ atmosphere without any target gas molecules, recombination of photogenerated electrons and holes can take place at trap sites like vacancies. Any existence of $\mathrm{O}_{2}$ like ambient air can passivate the trap sites to reduce recombination, increasing the current level. In other words, the presence of $\mathrm{O}_{2}$ in the atmosphere can reduce active sites for target gas molecules to decrease sensor responses, as shown in Fig. 9g. Similarly, the introduction of target gas molecules like VOCs in the $\mathrm{N}_{2}$ atmosphere can passivate the trap sites of $\mathrm{CsPbBr}_{2} \mathrm{I}$ to reduce the recombination and increase the current level to function as gas sensors. These unique gas sensing properties and mechanisms of inorganic halide perovskites reported by A. Tricoli's group can provide a new insight toward the design of low-power consuming gas sensors.

H.-Y. Li et al. reported light-activated gas sensing properties of CdS taking advantage of its low bandgap $(\sim 2.4 \mathrm{eV})$ and resistance. ${ }^{42}$ The low bandgap enables visible light absorption by CdS. The authors synthesized 2D CdS nanoflake arrays using chemical vapor deposition methods and investigated $\mathrm{NO}_{2}$ sensing characteristics under illumination by a fluorescent lamp and solar light at room temperature. Fig. 10a-d show the structural characterizations of the synthesized CdS nanoflake arrays. Hexagonal CdS nanoflakes with 10-20 nm thickness with a densely packed bottom region and a loosely packed top region can be confirmed. Therefore, highly porous nanostructures could be formed at the top surface, which is beneficial for the accessibility of target gas molecules. Fig. 10e shows the $I-V$ curves of CdS nanoflake arrays under different light sources in 

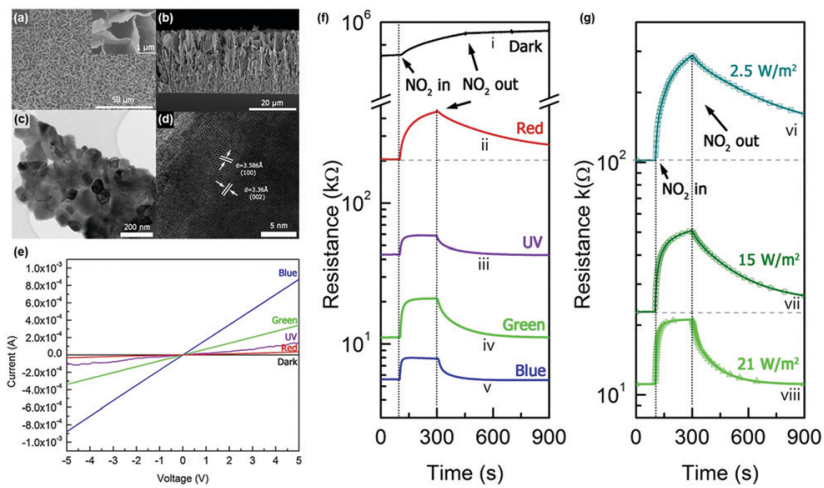

Fig. 10 (a) Top-view and (b) cross-sectional view SEM image (c) and highresolution TEM image (d) of the CdS nanoflake array gas sensor. (e) I-V curves of $\mathrm{CdS}$ nanoflake arrays under different light sources in air. ( $f$ and $g$ ) $\mathrm{CdS}$ nanoflake arrays sensor's response to $5 \mathrm{ppm} \mathrm{NO}$ (f) under different light sources and (g) various green LED irradiance. Reproduced with permission from ref. 42. Copyright (C) 2018 Elsevier B. V.

ambient air. The CdS nanoflake arrays reacted to all light wavelengths with their highest response to blue wavelengths. The response toward UV light was lower than that toward blue light, and this can be attributed to a lower light intensity and a relatively high recombination rate that originated from the excessively high photon energy. Upon exposure to $5 \mathrm{ppm} \mathrm{NO}_{2}$ under the illumination of different light sources, CdS nanoflake arrays exhibited varying gas sensing characteristics, as shown in Fig. 10f. The gas responses of CdS nanoflake arrays were highest under red wavelength, but the recovery characteristics were not impressive. The response and recovery were fast under blue and green wavelengths, while the gas response was higher under green wavelength than under blue wavelength. The gas response was the lowest under UV illumination. Collectively, the authors chose green light as an optimal light source to activate gas sensors based on CdS nanoflake arrays. Fig. 10g shows the gas sensing curves of CdS nanoflake arrays under irradiation by various green light sources. Although gas responses were highest under the lowest irradiance of $2.5 \mathrm{~W} \mathrm{~m}^{-2}$, the gas response under $21 \mathrm{~W} \mathrm{~m}^{-2}$ irradiance was still enough to distinguish the sensor signals, and highly promoted response time and recovery time under $21 \mathrm{~W} \mathrm{~m}^{-2}$ were considered important for the potential real application. The various measurements under optimized conditions exhibited highly sensitive and selective behaviors toward $\mathrm{NO}_{2}$ gas with an excellent linear relationship between the gas response and $\mathrm{NO}_{2}$ concentrations, indicating the capability of sensor calibration. The authors also demonstrated light activation under natural solar light irradiation, which exhibited acceptable light-activated gas sensing properties. The gas sensing mechanism follows conventional gas sensing models for light-activated gas sensors that are mentioned in the previous sections. The application of low-bandgap materials such as CdS can utilize visible light illumination as an activation source and reduce any potential damage induced when using light with high photon energy.

$\mathrm{X}$. Tian et al. reported the utilization of perylenediimide on $\mathrm{SnO}_{2}$ for the visible light-activated gas sensing properties. ${ }^{53}$
The perylenediimide is an n-type organic semiconductor that has the high planarity of large conjugated systems, resulting in extremely high chemical, thermal, and optical stability under visible light illumination. ${ }^{108-110}$ While pristine $\mathrm{SnO}_{2}$ can only be activated under UV irradiation, the introduction of perylenediimide enables the activation under visible light illumination. Fig. 11a shows the SEM image of pristine $\mathrm{SnO}_{2}$ films and Fig. 11b and c show the SEM images of the perylenediimidesensitized $\mathrm{SnO}_{2}$ film. Perylenediimide exhibits a morphology of fibril structures induced by the strong $\pi-\pi$ stacking interaction between perylenediimide skeletons along the long axial direction. Perylenediimide formed network structures on the surface of the $\mathrm{SnO}_{2}$ film. Fig. 11d and e show the dynamic response curves of perylenediimide-sensitized $\mathrm{SnO}_{2}$ and pristine $\mathrm{SnO}_{2}$ toward $0.5 \mathrm{ppm} \mathrm{NO}_{2}$ under the dark and light-illuminated conditions, respectively. The gas sensing reaction and recovery to baseline resistance under dark conditions take more than an hour for both samples, which is not practical at all. However, they were dramatically shortened under visible light illumination to a time scale of several minutes (response time of $6 \mathrm{~min}$ and recovery time of $4 \mathrm{~min}$, respectively). The overall gas responses of perylenediimide-sensitized $\mathrm{SnO}_{2}$ were also significantly increased to 131.60 , which is 4 times higher than that under dark conditions. Fig. 11f shows the dynamic response curves of perylenediimide-sensitized $\mathrm{SnO}_{2}$ to different concentrations of $\mathrm{NO}_{2}$ (250 ppb-4 ppm), and Fig. 11g shows the corresponding gas responses as a function of $\mathrm{NO}_{2}$ concentrations. The gas
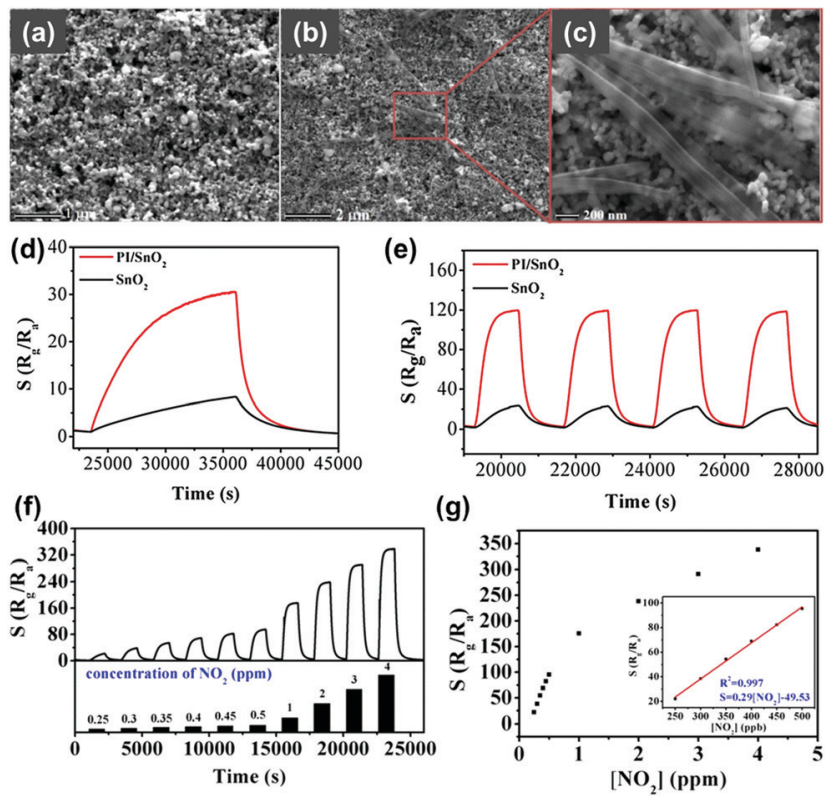

Fig. 11 (a) SEM image of the $\mathrm{SnO}_{2}$ film. (b and c) SEM images of the perylenediimide-sensitized $\mathrm{SnO}_{2}$ hybrid film. ( $d$ and e) Dynamic response curves of perylenediimide-sensitized $\mathrm{SnO}_{2}$ and pure $\mathrm{SnO}_{2}$ towards 0.5 ppm $\mathrm{NO}_{2}$ (d) without and (e) with visible-light illumination. (f) Dynamic response curves of perylenediimide-sensitized $\mathrm{SnO}_{2}$ to different concentrations of $\mathrm{NO}_{2}$ (250 ppb-4 ppm). (g) The corresponding response with different $\mathrm{NO}_{2}$ concentrations. The inset presents the acceptable response at low $\mathrm{NO}_{2}$ concentrations and the linear equation. Reproduced with permission from ref. 53. Copyright (C) 2019 Elsevier B. V. 
responses and $\mathrm{NO}_{2}$ concentrations exhibit an excellent linear relationship, indicating the capability of sensor calibration. Upon exposure to various gases, the perylenediimide-sensitized $\mathrm{SnO}_{2}$ exhibited highly sensitive and selective detection of $\mathrm{NO}_{2}$ under visible light illumination. The gas sensing mechanism also follows the conventional model for the light-activated gas sensors that are explained earlier in this review. The utilization of organic semiconductors with low-bandgap energy to metal oxides can facilitate visible light absorption to prevent potential disadvantages caused by UV illumination.

\section{Various strategies for future applications}

\subsection{Plasmonic nanoparticles}

The most challenging obstacle for the light-activated gas sensors toward further practical application is the lacking sensitivity toward various VOCs other than $\mathrm{NO}_{2}$. The lack of VOC selectivity originates from insufficient activation energy to overcome the water formation energy and promote oxidation of reducing gases under light illumination at room temperature.$^{68}$ Although various efforts for the utilization of several different materials and their combinations for light-activated gas sensing have been made, the lack of selectivity was difficult to overcome unless the reaction occurs at high operating temperatures. Therefore, incorporation of noble metal nanoparticles (Pt, Au, Ag, Pd, etc.) can be a good strategy since they can promote gas sensing reactions to specific target gas molecules. ${ }^{111-119}$ Moreover, the noble metal nanoparticles exhibit localized surface plasmon resonance (LSPR) effects under the illumination of resonant wavelengths to supply additional hot electrons to participate in the chemical reaction.

F. Xu et al. reported the light-activated gas sensing properties of Au nanoparticles-decorated $\mathrm{ZnO}$ nanotetrapods taking advantage of plasmonic resonant energy from $\mathrm{Au}$ nanoparticles. ${ }^{38}$ Fig. 12a-d show the schematic of the gas sensor fabrication process. ZnO nanotetrapods were deposited through thermal evaporation on Au electrode-patterned ceramic plates, followed by $5 \mathrm{~nm}$ Au sputter deposition and agglomeration into nanoparticles via annealing. Fig. 12e shows the SEM image of pristine ZnO nanotetrapods and Fig. 12f shows the SEM image of Au nanoparticle-decorated $\mathrm{ZnO}$ nanotetrapods. The porous network of $\mathrm{ZnO}$ nanotetrapods is expected to provide excellent gas molecule accessibility, and the diameter of agglomerated $\mathrm{Au}$ nanoparticles ranges from 7 to $50 \mathrm{~nm}$ with uniform spatial distribution. Upon exposure to $500 \mathrm{ppm} \mathrm{C}_{2} \mathrm{H}_{5} \mathrm{OH}$, as shown in Fig. 12g, both pristine $\mathrm{ZnO}$ nanotetrapods and Au nanoparticledecorated ZnO nanotetrapods exhibited almost no gas response at $17^{\circ} \mathrm{C}$. Under white light illumination $\left(6 \mathrm{~mW} \mathrm{~mm}^{-2}\right)$, pristine samples exhibited a small increase in gas response, whereas $\mathrm{Au}$ nanoparticle-decorated samples exhibited dramatically enhanced gas response. The stable operation toward multiple pulses of $\mathrm{C}_{2} \mathrm{H}_{5} \mathrm{OH}$ under light illumination was also confirmed, as shown in Fig. 12h. The Au nanoparticle-decorated $\mathrm{ZnO}$ nanotetrapods were then exposed to various VOCs including $\mathrm{C}_{2} \mathrm{H}_{5} \mathrm{OH}, \mathrm{CH}_{3} \mathrm{COCH}_{3}$, $\mathrm{HCHO}$, and $\mathrm{CH}_{3} \mathrm{OH}$, as shown in Fig. 12i. Under light illumination,

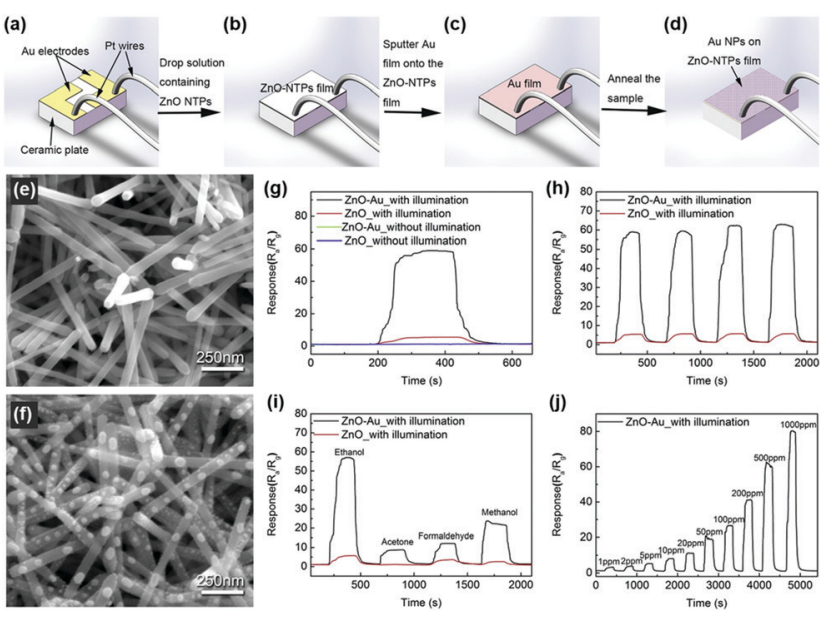

Fig. 12 Schematic of the gas sensor fabrication process. (a) Ceramic substrate: two Au pad electrodes pre-deposited on the surface and two Pt wires mounted on the Au electrodes; (b) $\mathrm{ZnO}$ deposited on the ceramic substrate; (c) $5 \mathrm{~nm}$ Au film covered $\mathrm{ZnO}$-based sensor; (d) final sensor device with ZnO decorated with Au NPs. (e and f) SEM images of the sensor devices with (e) pure ZnO and (f) Au NP-decorated ZnO. (g-j) Realtime sensing response curves of sensors made of pure $\mathrm{ZnO}$ and Au NPdecorated $\mathrm{ZnO}$ at $17{ }^{\circ} \mathrm{C}$. (g) Exposure to 500 ppm $\mathrm{C}_{2} \mathrm{H}_{5} \mathrm{OH}$. (h) Cyclic repeated exposure to $500 \mathrm{ppm} \mathrm{C}_{2} \mathrm{H}_{5} \mathrm{OH}$ under white light illumination. (i) Sequential exposure to $500 \mathrm{ppm}$ of different gases including $\mathrm{C}_{2} \mathrm{H}_{5} \mathrm{OH}$, $\mathrm{CH}_{3} \mathrm{COCH}_{3}, \mathrm{HCHO}$ and $\mathrm{CH}_{3} \mathrm{OH}$ with devices under white light illumination. (j) Exposure to different concentration levels of $\mathrm{C}_{2} \mathrm{H}_{5} \mathrm{OH}$ vapor (1-1000 ppm) with devices made of Au NP-decorated $\mathrm{ZnO}$ under white light illumination. Reproduced with permission from ref. 38. Copyright (C) 2018 Elsevier B. V.

gas responses to all gases were dramatically enhanced, and the gas response toward $\mathrm{C}_{2} \mathrm{H}_{5} \mathrm{OH}$ exhibited the highest value. Fig. 12j shows the light-activated gas sensing properties of $\mathrm{Au}$ nanoparticle-decorated $\mathrm{ZnO}$ nanotetrapods toward different concentration levels of $\mathrm{C}_{2} \mathrm{H}_{5} \mathrm{OH}(1-1000 \mathrm{ppm})$. The gas response and gas concentration exhibited an excellent linear relationship, indicating the capability of practical application. Since the conducting channel of the gas sensors is $\mathrm{ZnO}$, the overall light-activated gas sensing mechanism follows that of conventional metal oxides. In addition to the conventional mechanisms, the decoration of $\mathrm{Au}$ nanoparticles increased the Schottky barrier at the interface of $\mathrm{Au}$ and $\mathrm{ZnO}$ due to a difference in work function, contributing to the suppression of the recombination of photogenerated charge carriers. ${ }^{120}$ Moreover, under white light illumination that includes $532 \mathrm{~nm}$ wavelength, the resonant wavelength for $\mathrm{Au}$ nanoparticles can induce LSPR absorption. Therefore, Au nanoparticles can enhance light absorption and broaden the available wavelength range that pristine ZnO cannot achieve. ${ }^{121,122}$ Through LSPR, highly energetic hot electrons are generated in Au nanoparticles and they can be transported to the conduction band of $\mathrm{ZnO}$ through the increased Schottky barrier at the interface. They can participate in the photocatalytic oxygen adsorption process, and localized field enhancement around Au nanoparticles through LSPR can facilitate the generation and separation of photogenerated electron and hole pairs.

R. Chen, et al. prepared oxygen vacancy-enriched $\mathrm{ZnO}$ nanorod/Pd nanoparticle hybrids for light-activated gas sensing. ${ }^{39}$ 


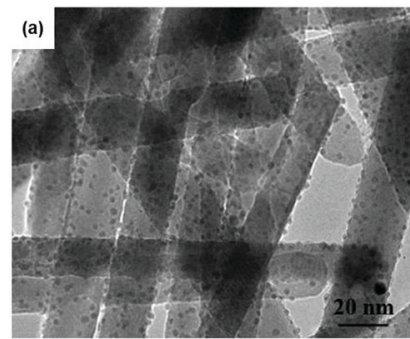

(b)
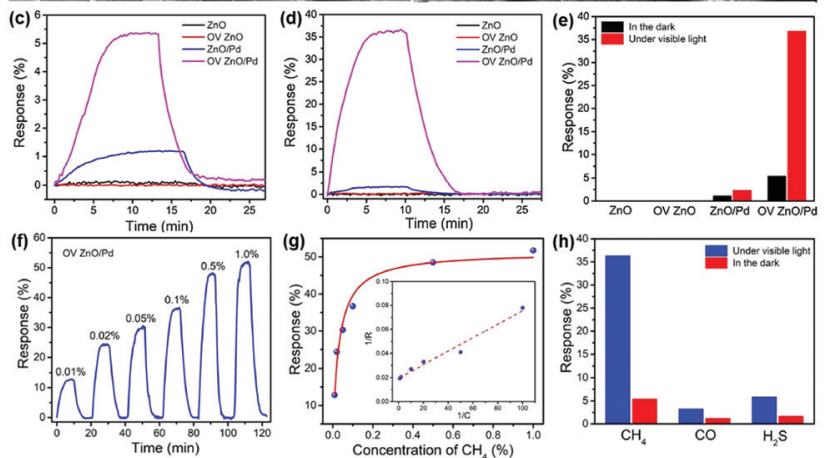

Fig. 13 TEM images of the (a) $\mathrm{ZnO} / \mathrm{Pd}$ and (b) OV $\mathrm{ZnO} / \mathrm{Pd}$ samples. (c) Dynamic response curves of the sensors based on the $\mathrm{ZnO}$, OV $\mathrm{ZnO}$, $\mathrm{ZnO} / \mathrm{Pd}$ and $\mathrm{OV} \mathrm{ZnO} / \mathrm{Pd}$ samples to $0.1 \% \mathrm{CH}_{4}$ in the darkness and (d) under $590 \mathrm{~nm}$ light illumination $\left(6 \mathrm{~mW} \mathrm{~cm} \mathrm{~cm}^{-2}\right)$, and (e) the corresponding gas sensing responses. (f) Dynamic response curve and (g) fitted responses of the OV $\mathrm{ZnO} / \mathrm{Pd}$ sensor to $0.01-1 \% \mathrm{CH}_{4}$ under $590 \mathrm{~nm}$ light illumination $\left(6 \mathrm{~mW} \mathrm{~cm}^{-2}\right)$. (h) Selectivity of the OV $\mathrm{ZnO} / \mathrm{Pd}$ sensor to $0.1 \%$ $\mathrm{CH}_{4}$ over $\mathrm{CO}$ and $\mathrm{H}_{2} \mathrm{~S}$ under $590 \mathrm{~nm}$ light illumination $\left(6 \mathrm{~mW} \mathrm{~cm} \mathrm{~cm}^{-2}\right.$ ). Reproduced with permission from ref. 39. Copyright (C) 2020 Elsevier B.V.

The authors treated $\mathrm{ZnO}$ nanorods with $\mathrm{H}_{2}(10 \%$ in $\mathrm{Ar})$ to realize oxygen vacancy-enriched nature, followed by the dispersion of Pd nanoparticles by a solvent reduction method. Fig. 13a and b show the transmission electron microscopic (TEM) images of the normal $\mathrm{ZnO} / \mathrm{Pd}$ hybrid and the oxygen vacancy-enriched $\mathrm{ZnO} / \mathrm{Pd}$ hybrid, respectively. Although oxygen vacancies cannot be distinguished in the TEM images, uniformly distributed Pd nanoparticles on $\mathrm{ZnO}$ nanorods can be confirmed. The existence of oxygen vacancies was confirmed by X-ray photoelectron spectroscopy analysis through increased oxygen vacancy peaks. Fig. 13c and d show the dynamic response curves of each fabricated gas sensor toward $0.1 \%$ $\mathrm{CH}_{4}$ under the dark and $590 \mathrm{~nm}$ light-illuminated conditions (6 $\mathrm{mW} \mathrm{cm}^{-2}$ ), respectively. The corresponding gas response values are summarized in Fig. 13e. The pristine $\mathrm{ZnO}$ nanorods and oxygen vacancy-enriched $\mathrm{ZnO}$ nanorods did not exhibit any gas response to $\mathrm{CH}_{4}$, well-known chemically inert explosive gas, under both dark and light-illuminated conditions. ${ }^{123}$ This indicates that oxygen vacancy alone cannot contribute to the light-activated $\mathrm{CH}_{4}$ sensing at low temperatures. $\mathrm{ZnO} / \mathrm{Pd}$ hybrids without oxygen vacancy enrichment exhibit a little gas response under the dark condition and a slightly increased gas response under light-illuminated conditions. The dispersion of Pd nanoparticles was effective in promoting $\mathrm{CH}_{4}$ sensing even under dark conditions due to the catalytic effects of Pd nanoparticles. The oxygen vacancy-enriched $\mathrm{ZnO} / \mathrm{Pd}$ hybrids exhibited a higher gas response under the dark condition and a dramatically enhanced gas response under light-illuminated conditions, indicating that the synergistic effects of oxygen vacancies and $\mathrm{Pd}$ nanoparticles play a critical role in lightactivated $\mathrm{CH}_{4}$ sensing. Fig. $13 \mathrm{f}$ and $\mathrm{g}$ show the dynamic response curves and fitted responses of the oxygen vacancyenriched $\mathrm{ZnO} / \mathrm{Pd}$ hybrid gas sensors to different concentrations of $\mathrm{CH}_{4}(0.01-1 \%)$ under light illumination. The sensors exhibited properties following the Langmuir isotherm adsorption model and revealed their capability of reliable operation as practical gas sensors. Upon exposure to three different target gases $\left(\mathrm{CH}_{4}\right.$, $\mathrm{CO}$, and $\left.\mathrm{H}_{2} \mathrm{~S}\right)$, oxygen vacancy-enriched $\mathrm{ZnO} / \mathrm{Pd}$ hybrids exhibited highly selective detection of $\mathrm{CH}_{4}$ under light illumination (Fig. 13h). The highly enriched oxygen vacancies can function as strong electron donors for the promotion of the photocatalytic oxygen adsorption process along with hot electrons generated from LSPR of Pd nanoparticles under $590 \mathrm{~nm}$ light illumination. At the $\mathrm{ZnO}$ and $\mathrm{Pd}$ interface, the Schottky barrier should be formed due to work function difference, and this Schottky barrier blocks easy transfer of hot electrons generated from Pd nanoparticles through LSPR. ${ }^{124}$ The oxygen vacancies can lower the energy barrier to bring generated hot electrons to $\mathrm{ZnO}$ nanorods for photocatalytic oxygen adsorption and the light-activated $\mathrm{CH}_{4}$ sensing.

\subsection{Nanostructures}

The formation of nanostructures can be another good strategy to enhance light-activated gas sensing properties. Some of the previously reviewed works in this paper also adopted various nanostructures for better gas sensing properties, but most of them took advantage of increased surface area and provided no more detailed explanation beyond that. ${ }^{38,39,42,50,63}$ In fact, the differences in the nanostructural morphologies provide varying fractions of exposed polar facets, resulting in different lightactivated gas sensing properties.

J. Cui et al. synthesized ZnO nanofibers, nanoplates, and nanoflowers by simple electrospinning and hydrothermal methods. ${ }^{43}$ Compared to other metal oxides, ZnO has distinctive growth directions that make it facile to realize various $\mathrm{ZnO}$ nanostructures through simple control of growth conditions. ${ }^{125}$ Fig. 14a-c show the SEM images of ZnO nanoplates, nanoflowers, and nanofibers, respectively. The $\mathrm{ZnO}$ nanoplates have a hexagonal morphology with $4 \mu \mathrm{m}$ diameter and $400 \mathrm{~nm}$ thickness, and the ZnO nanoflowers exhibit 3D nanostructures with a diameter in the range of 4-5 $\mu \mathrm{m}$, which are composed of numerous nanosheets with $80 \mathrm{~nm}$ thickness. The $\mathrm{ZnO}$ nanofibers have a diameter of 500-600 nm, and they are composed of tiny nanocrystallites, while the previous two morphologies (nanoplates and nanoflowers) have a relatively smooth surface. The fabricated gas sensors based on each $\mathrm{ZnO}$ nanostructure were exposed to different concentrations of $\mathrm{HCHO}$ under $365 \mathrm{~nm}$ UV light illumination at room temperature, as shown in Fig. 14d-f. Fig. 14g summarizes the gas responses of the gas sensors with each $\mathrm{ZnO}$ nanostructure toward HCHO. Among the three nanostructures, $\mathrm{ZnO}$ nanofibers exhibited the highest gas response, which was 6.7 times and 2.5 times higher than that of $\mathrm{ZnO}$ nanoplates and $\mathrm{ZnO}$ nanoflowers, respectively. These could be attributed to a higher specific area for $\mathrm{ZnO}$ 

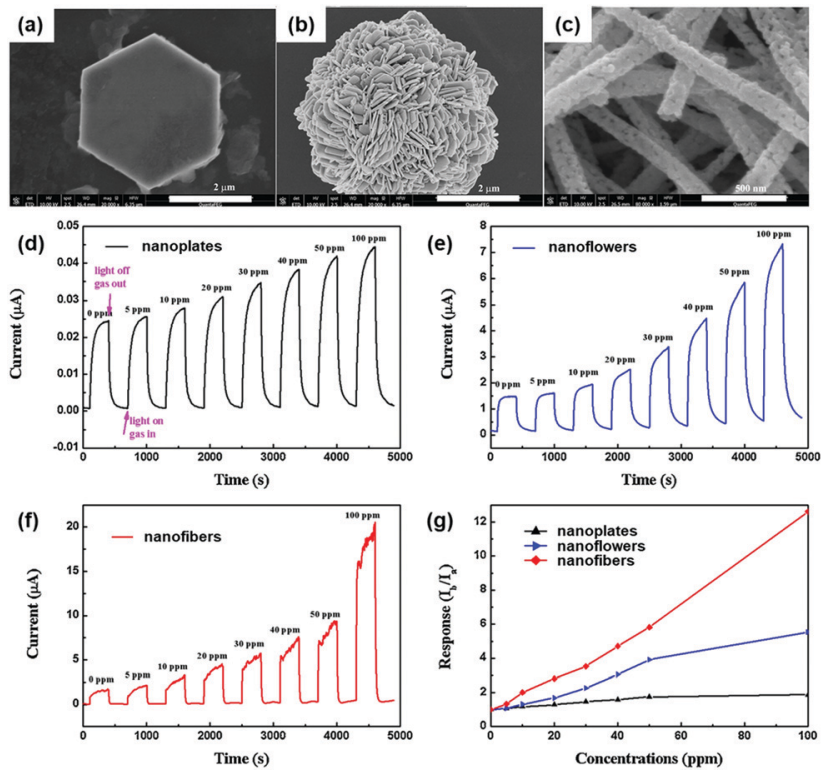

Fig. 14 SEM images of (a) ZnO nanoplates, (b) ZnO nanoflowers, and (c) $\mathrm{ZnO}$ nanofibers. The current response cycles of (d) $\mathrm{ZnO}$ nanoplates, (e) $\mathrm{ZnO}$ nanoflowers and (f) $\mathrm{ZnO}$ nanofibers to different concentrations of formaldehyde and $(\mathrm{g})$ the gas-sensing responses with a bias voltage of $10 \mathrm{~V}$ under $365 \mathrm{~nm}$ light irradiation at room temperature. Reproduced with permission from ref. 43. Copyright (C) 2016 Elsevier B. V.

nanofibers and polycrystalline structure with a large number of grain boundaries. The overall gas sensing mechanism follows that of conventional light-activated gas sensing. The photocatalytically adsorbed oxygen molecules that are loosely bound to the surface provide much more sensitive detection of target gas molecules. Since $\mathrm{ZnO}$ nanofibers in this study are composed of numerous nanocrystallites with an average size of $45 \mathrm{~nm}$, Schottky barriers formed at each grain boundary after oxygen adsorption and its charge transfer contribute to the sensitive modulation upon adsorption and desorption of target gas molecules. ${ }^{126}$ However, $\mathrm{ZnO}$ nanoplates and nanoflowers have fewer grain boundaries to result in thinner depletion layers than $\mathrm{ZnO}$ nanofibers. In fact, three $\mathrm{ZnO}$ nanostructures have been prepared by different preparation methods from each other and that may have caused a significant influence on the light-activated gas sensing characteristics for each. Still, this study has revealed the importance of grain size and grain boundary density to light-activated gas sensing properties, providing important parameters for nanostructure designs.

M. R. Alenezi et al. reported the UV light-activated gas sensing properties of three $\mathrm{ZnO}$ nanostructures (nanowires, nanodisks, and nanostars), which were all prepared by hydrothermal synthesis. ${ }^{44}$ Each nanostructure exhibits different ratios of exposed polar to nonpolar facets, and they can significantly affect light-activated gas sensing characteristics. Fig. 15a-c show the SEM images of $\mathrm{ZnO}$ nanowires, $\mathrm{ZnO}$ nanodisks, and $\mathrm{ZnO}$ nanostars, respectively. The photograph of the fabricated gas sensors based on $\mathrm{ZnO}$ nanostructures on flexible substrates is shown in Fig. 15d. ZnO nanowires exhibited $200 \mathrm{~nm}$ diameter and $8 \mu \mathrm{m}$ length, and they have been formed through the growth
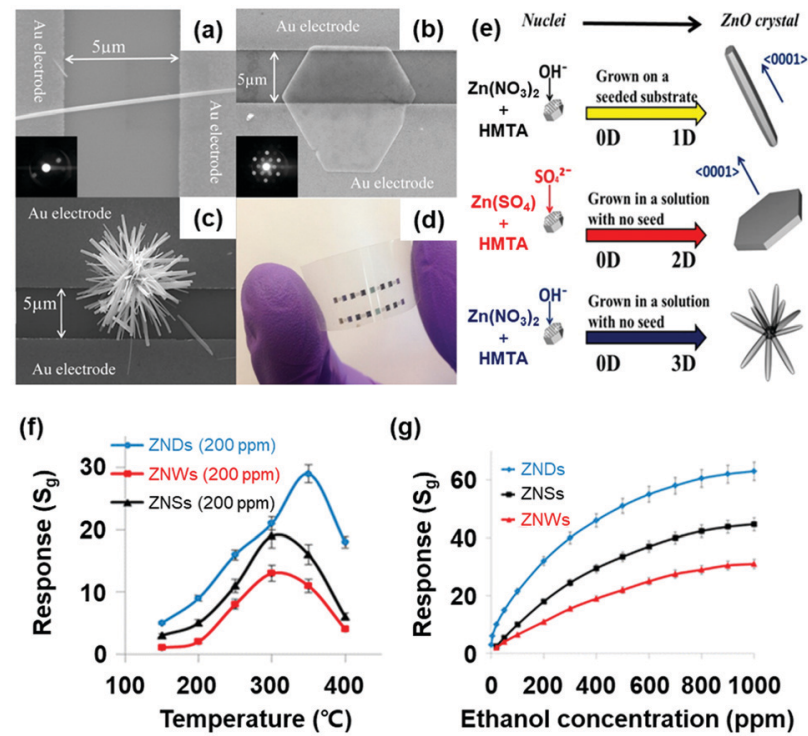

(g)
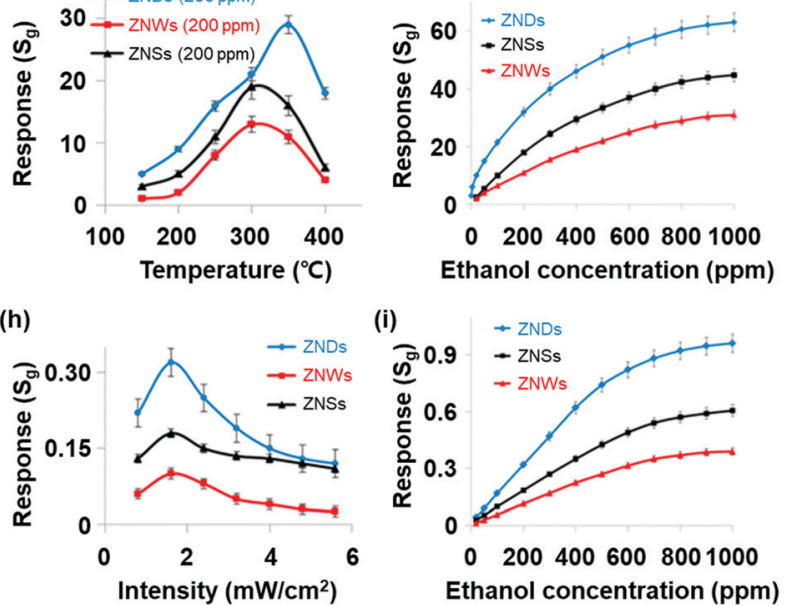

Fig. 15 (a) SEM image of a $\mathrm{ZnO}$ nanowires (inset: SAED pattern), (b) ZnO nanodisks (inset: SAED pattern of ZNDs), and (c) ZnO nanostars. (d) Photograph of $\mathrm{ZnO}$ nanostructured sensors on a flexible substrate. (e) Schematic diagram of the growth process for each $\mathrm{ZnO}$ nanostructure. (f) Responses to 200 ppm $\mathrm{C}_{2} \mathrm{H}_{5} \mathrm{OH}$ at different temperatures. (g) Response vs time curves to different $\mathrm{C}_{2} \mathrm{H}_{5} \mathrm{OH}$ concentrations at $350{ }^{\circ} \mathrm{C}$. (h) Responses to 200 ppm of $\mathrm{C}_{2} \mathrm{H}_{5} \mathrm{OH}$ at different light intensities. (i) Response vs time curves to different $\mathrm{C}_{2} \mathrm{H}_{5} \mathrm{OH}$ concentrations at $1.6 \mathrm{~mW} \mathrm{~cm}{ }^{-2}$. Reproduced with permission from ref. 44. Copyright (C) 2013 American Chemical Society.

direction of [0001], resulting in their nonpolar side surface with the $\{10 \overline{1} 0\}$ orientation exposed. ${ }^{127,128} \mathrm{ZnO}$ nanodisks have several tens of nanometer-scale thickness with high transparency, as shown in SEM images, and they have grown in a perpendicular direction to [0001]. Lastly, ZnO nanostars are composed of several nanowires with 150-200 $\mathrm{nm}$ diameter and expected to have similar crystallographic characteristics to $\mathrm{ZnO}$ nanowires. Fig. 15e summarizes the growth conditions of each ZnO nanostructure. According to the X-ray diffraction (XRD) analysis for each nanostructure, intensity ratios of the (0002) polar plane to the $(10 \overline{1} 0)$ nonpolar plane were calculated to be $0.36,2.10$, and 0.50 for $\mathrm{ZnO}$ nanowires, nanodisks, and nanostars, respectively. ZnO nanodisks exposed relatively more polar facets to air, while the other two morphologies exposed relatively nonpolar facets. The fabricated gas sensors based on $\mathrm{ZnO}$ nanowires, nanodisks, and nanostars were exposed to $200 \mathrm{ppm}$ $\mathrm{C}_{2} \mathrm{H}_{5} \mathrm{OH}$ under different operating temperatures, and their results are summarized in Fig. $15 \mathrm{f}$ and $\mathrm{g}$. The $\mathrm{ZnO}$ nanodisks exhibited the highest gas response at all operating temperatures over ZnO nanowires and nanostars. The optimal operating temperature exists since higher temperatures provide 
higher energy for surface activation, while excessively high operating temperatures accelerate the desorption kinetics of the sensing materials to yield lower gas responses. ${ }^{129}$ The UV light-activated gas sensing properties of the gas sensors at room temperature are summarized in Fig. $15 \mathrm{~h}$ and i. The $\mathrm{ZnO}$ nanodisks exhibited the highest gas responses under all UV light intensities, corresponding to the thermally activated gas sensing results. As did for all metal oxide-based light-activated gas sensors, the photocatalytically adsorbed oxygen molecules play a critical role in the sensitive gas sensing characteristics of ZnO nanodisks under light activation. In addition to photocatalytic activation, $\mathrm{ZnO}$ nanodisks exhibited higher intensity ratios of the (0002) polar plane to the (1010) nonpolar plane than other morphologies as mentioned before. The (0001) polar facet of $\mathrm{ZnO}$ nanodisks is terminated with $\mathrm{Zn}^{2+}$ ions in $\mathrm{ZnO}$ crystal lattices, and they are favorable active sites for oxygen adsorption. However, the $\{10 \overline{1} 0\}$ nonpolar planes for $\mathrm{ZnO}$ nanowires and nanostars have equivalent $\mathrm{Zn}$ and $\mathrm{O}$ atoms at the termination of the $\mathrm{ZnO}$ lattice, leading to less oxygen adsorption. Therefore, $\mathrm{ZnO}$ nanodisks could exhibit the highest chemisorption ability for the gas sensing reaction, resulting in the highest gas responses under UV light illumination.

\subsection{Micro-LED integration}

As reviewed, various materials including metal oxides, 2D materials, inorganic perovskites, metal sulfides, and organic semiconductors have been utilized to develop high-performance light-activated gas sensors. Certainly, the light-activation exhibited promising gas sensing characteristics and visualized their possibility and capabilities of replacing currently dominating thermally activated gas sensors in aspects of both performance and power consumption. However, the structure of the sensor devices should also be studied considering the practical application of lightactivated gas sensors. Current thermally activated gas sensors have heater electrodes integrated under the gas sensing electrodes on a single substrate. However, current light-activated gas sensors utilize separate light sources that are not integrated on a single substrate, making them reluctant for practical applications. Therefore, further efforts on integration of light sources to gas sensor devices should be proceeded to get close to the real application of the light-activated gas sensors. ${ }^{130-132}$

I. Cho, et al. reported monolithic micro-LEDs/metal oxide nanowire gas sensors that exhibit microwatt-level power consumption. ${ }^{45}$ Fig. 16a and b show the schematic illustrations of the proposed monolithic gas sensors on micro-LEDs. The device has two contact pads for LED operation and the other two electrodes for gas sensor operation. The GaN-based microLEDs exhibit a peak emission wavelength of $390 \mathrm{~nm}$, enough to activate metal oxides. The upper area of micro-LED was passivated via chemical vapor deposition of $\mathrm{SiO}_{2}$, and hydrothermally grown $\mathrm{ZnO}$ nanowires were located on the interdigitated electrodes on the top of the $\mathrm{SiO}_{2}$ passivation layer. Fig. 16c-e show the optical microscopic images of the devices with different widths of micro-LED (200, 100, and $30 \mu \mathrm{m}$, respectively). Fig. 16f shows the optical microscopic image of the device with a $30 \mu \mathrm{m}$ LED width under operation. The SEM images of the
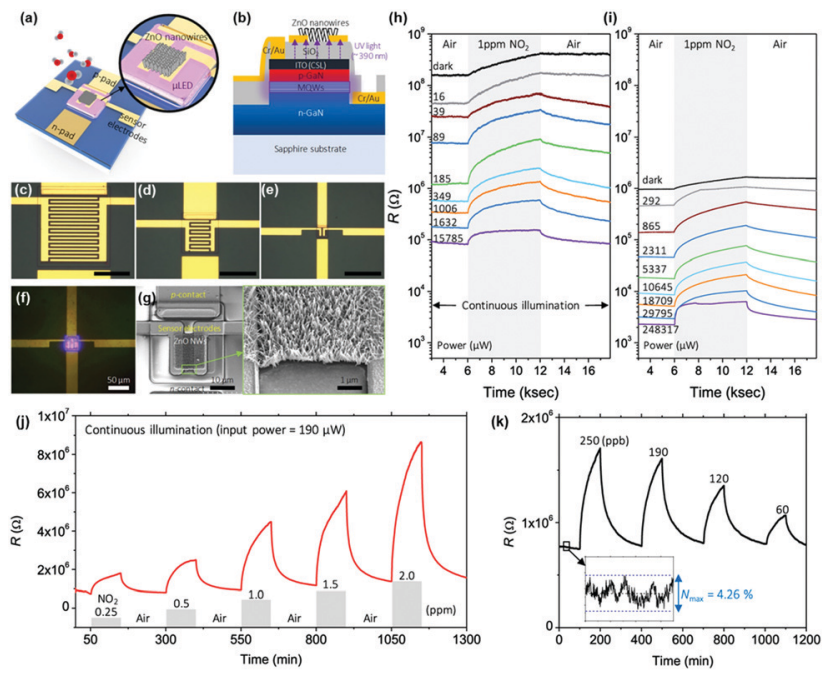

Fig. 16 Schematic of the proposed monolithic photoactivated gas sensors on a microLED platform ( $\mu \mathrm{LP}$ ): (a) top view and (b) cross-sectional view. Optical microscopic images of fabricated LPs are as follows: (c-e) $200 \times 200(200-L P), 100 \times 100(100-L P)$, and $30 \times 30(30-\mu L P) \mu m^{2}$, respectively. Scale bars are $100 \mu \mathrm{m}$. (f) Optical microscopic image of a turned-on 30- $\mu \mathrm{LP}$ (forward bias = $5 \mathrm{~V}$ ). (g) SEM images of synthesized zinc oxide $(\mathrm{ZnO})$ nanowires on a prefabricated 30- $\mu \mathrm{LP}$. Responses of monolithic photoactivated gas sensors on (h) 30- $\mu$ LP and (i) 200-LP to $1 \mathrm{ppm}$ $\mathrm{NO}_{2}$ gas under different input electrical powers. $\mathrm{NO}_{2}$ sensing performance of the photoactivated gas sensor on 30- $\mu \mathrm{LP}$. Whole tests were conducted under an operating power of $\sim 190 \mu \mathrm{W}$ : dynamic response to (j) $0.25-2 \mathrm{ppm}$ and $\left(\mathrm{k}\right.$ ) 60-250 ppb $\mathrm{NO}_{2}$ gas. The inset graph shows the noise level of the measurement. Reproduced with permission from ref. 45. Copyright (C) 2020 American Chemical Society.

synthesized $\mathrm{ZnO}$ nanowires on the fabricated device can be clearly seen in Fig. 16g. Then, the fabricated devices with different widths were exposed to $1 \mathrm{ppm} \mathrm{NO}_{2}$ gas with varying input powers to micro-LEDs, as shown in Fig. 16h and i. The base resistance of the device decreases as the input power to micro-LEDs increases, indicating a higher number of photogenerated charge carriers under a higher micro-LED power. The overall resistance for the device with $30 \mu \mathrm{m}$ width is higher than that for the device with $200 \mu \mathrm{m}$ width. This could be attributed to a limited conduction path through $\mathrm{ZnO}$ nanowires for the devices with a small width, since the gap between each electrode $(5 \mu \mathrm{m})$ is consistent for all devices. The sensor responses were the highest for the microLEDs with the smallest width $(30 \mu \mathrm{m})$, and the responses were not always the highest under the highest input power. These can be explained by the current spreading of micro-LEDs. With the increase in the width of micro-LEDs, the lateral series resistance increases and current spreading becomes inhomogeneous, leading to the possible less irradiating region to the gas sensing layers. These dead zones can be minimized by reducing the width of micro-LEDs, and this can support the highest gas responses for the devices with $30 \mu \mathrm{m}$-width micro-LEDs. The light-activated gas sensor responses are also highly dependent on the balance of surface absorbate density $\left(\mathrm{O}_{2}\right.$ and $\left.\mathrm{NO}_{2}\right)$. Under the dark condition, only pre-adsorbed oxygen exists on the surface, while all the absorbates are totally desorbed under the high flux of illuminated light. ${ }^{133}$ Therefore, there should be an optimal balance between 
dark and high flux conditions, and which resulted in the optimal input power to micro-LEDs to yield the highest gas responses. Fig. $16 \mathrm{j}$ and $\mathrm{k}$ show the dynamic responses to $0.25-2 \mathrm{ppm} \mathrm{NO}_{2}$ and 60-250 ppb $\mathrm{NO}_{2}$, respectively. These data well support the stable and reliable operation of the monolithic micro-LEDs/metal oxide nanowire gas sensors over a wide concentration range of target gases.

\section{Conclusion and perspective}

In this review, the recent progress of light-activated gas sensors was summarized. Light-activated gas sensing has started with UV illumination on metal oxides, and the available light spectrum range has been expanded to the visible light range by utilization of low-bandgap materials such as 2D materials. While metal oxides and 2D materials have been two major candidate materials for light-activated gas sensing, inorganic perovskites, metal sulfides, and conductive polymers also exhibited their potential for future applications. Despite their promising gas sensing properties under light illumination at room temperature, the lack of selectivity toward reducing gases remained a challenge necessitating future research due to insufficient activation energy for their oxidation. The studies on the effects of nanostructures provided a deeper understanding of light activation depending on the exposed crystallographic orientations. In particular, the utilization of plasmonic nanoparticles and their localized surface plasmon resonance effects can dramatically enhance the light-activated gas sensing performance. The plasmonic nanoparticles can broaden the available light wavelength range, enhance gas sensing properties by hot electron generation, and take advantage of the catalytic effect and chemical sensitization of noble metal nanoparticles. Moreover, the integration with micro-LEDs suggested a possible device structure for the practical application of the light-activated gas sensors (Fig. 17). Collectively, proper and systematic design of light-activated gas sensors based on the following parameters can provide a promising perspective toward future gas sensor applications for IoE: (i) principles of material selection (bandgap, heterojunctions, or plasmonic nanoparticles), (ii) design of nanostructures, (iii) device structures and fabrication methods, and (iv) overall gas sensing mechanisms considering the relationship between light

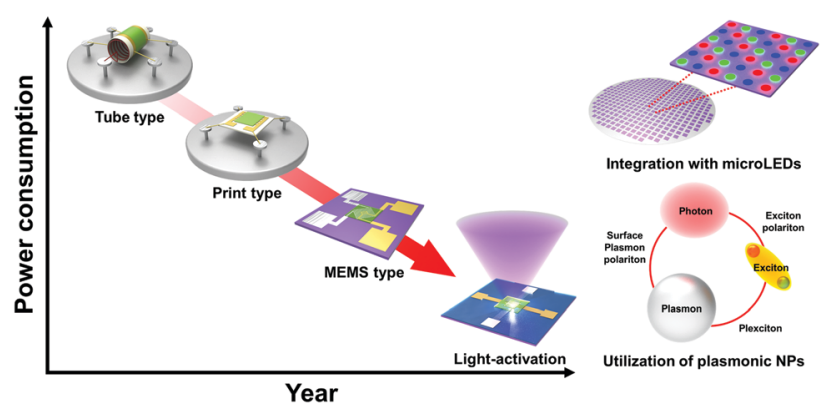

Fig. 17 Schematic of the future perspectives of the light-activated gas sensors. irradiation and gas sensing materials and the resulting gas sensing properties.

\section{Conflicts of interest}

The authors declare that there are no conflicts of interest.

\section{Acknowledgements}

This work was financially supported by Basic Science Research Program (2017R1A2B3009135), Nano·Material Technology Development Program (2016M3A7B4910), and Nuclear Energy R\&D Program (2020M2D8A206983011) through the National Research Foundation of Korea funded by the Ministry of Science and ICT.

\section{References}

1 R. A. Potyrailo, Chem. Rev., 2016, 116, 11877-11923.

2 J. B. A. Gomes, J. J. P. C. Rodrigues, R. A. L. Rabelo, N. Kumar and S. Kozlov, J. Sens. Actuator Netw., 2019, 8, 57.

3 D. Xie, D. Chen, S. Peng, Y. Yang, L. Xu and F. Wu, IEEE Electron Device Lett., 2019, 40, 1178-1181.

4 H. Yuan, J. Tao, N. Li, A. Karmakar, C. Tang, H. Cai, S. J. Pennycook, N. Singh and D. Zhao, Angew. Chem., Int. Ed., 2019, 58, 14089-14094.

5 I. A. Buryakov, T. I. Buryakov and V. T. Matsayev, J. Anal. Chem., 2016, 71, 234-242.

6 A. Paliwal, A. Sharma, M. Tomar and V. Gupta, Sens. Actuators, B, 2017, 250, 679-685.

7 B. Sharma and J.-S. Kim, Sci. Rep., 2018, 8, 5902.

8 X. Duan, S. Kamin and N. Liu, Nat. Commun., 2017, 8, 14606.

9 S. Mulmi and V. Thangadurai, J. Electrochem. Soc., 2020, 167, 037567.

10 Z. Duan, Y. Zhang, Y. Tong, H. Zou, J. Peng and X. Zheng, J. Electron. Mater., 2017, 46, 6895-6900.

11 S. Y. Park, Y. Kim, T. Kim, T. H. Eom, S. Y. Kim and H. W. Jang, InfoMat, 2019, 1, 289-316.

12 H. Tai, Z. Duan, Y. Wang, S. Wang and Y. Jiang, ACS Appl. Mater. Interfaces, 2020, 12, 31037-31053.

13 H. Tai, S. Wang, Z. Duan and Y. Jiang, Sens. Actuators, B, 2020, 318, 128104.

14 J. M. Suh, Y.-S. Shim, D. H. Kim, W. Sohn, Y. Jung, S. Y. Lee, S. Choi, Y. H. Kim, J.-M. Jeon, K. Hong, K. C. Kwon, S. Y. Park, C. Kim, J.-H. Lee, C.-Y. Kang and H. W. Jang, Adv. Mater. Technol., 2017, 2, 1600259.

15 J. M. Suh, W. Sohn, Y.-S. Shim, J.-S. Choi, Y. G. Song, T. L. Kim, J.-M. Jeon, K. C. Kwon, K. S. Choi, C.-Y. Kang, H.-G. Byun and H. W. Jang, ACS Appl. Mater. Interfaces, 2017, 10, 1050-1058.

16 Y. G. Song, J. Y. Park, J. M. Suh, Y.-S. Shim, S. Y. Yi, H. W. Jang, S. Kim, J. M. Yuk, B.-K. Ju and C.-Y. Kang, Chem. Mater., 2018, 31, 207-215. 
17 S. Y. Yi, Y. G. Song, J. Y. Park, J. M. Suh, G. S. Kim, Y.-S. Shim, J. M. Yuk, S. Kim, H. W. Jang, B.-K. Ju and C.-Y. Kang, ACS Appl. Mater. Interfaces, 2019, 11, 7529-7538.

18 D. H. Kim, T. H. Kim, W. Sohn, J. M. Suh, Y.-S. Shim, K. C. Kwon, K. Hong, S. Choi, H.-G. Byun, J.-H. Lee and H. W. Jang, Sens. Actuators, B, 2018, 274, 587-594.

19 Y.-S. Shim, B. Jang, J. M. Suh, M. S. Noh, S. Kim, S. D. Han, Y. G. Song, C.-Y. Kang, H. W. Jang and W. Lee, Sens. Actuators, B, 2018, 255, 1841-1848.

20 Y. G. Song, Y.-S. Shim, J. M. Suh, M.-S. Noh, G. S. Kim, K. S. Choi, B. Jeong, S. Kim, H. W. Jang, B.-K. Ju and C.-Y. Kang, Small, 2019, 15, 1902065.

21 H. Tai, Z. Duan, Z. He, X. Li, J. Xu, B. Liu and Y. Jiang, Sens. Actuators, B, 2019, 298, 126874.

22 Q. Zhao, Z. Duan, Z. Yuan, X. Li, S. Wang, B. Liu, Y. Zhang, Y. Jiang and H. Tai, Chin. Chem. Lett., 2020, 31, 2045-2049.

23 Y.-S. Shim, K. C. Kwon, J. M. Suh, K. S. Choi, Y. G. Song, W. Sohn, S. Choi, K. Hong, J.-M. Jeon, S.-P. Hong, S. Kim, S. Y. Kim, C.-Y. Kang and H. W. Jang, ACS Appl. Mater. Interfaces, 2018, 10, 31594-31602.

24 K. C. Kwon, J. M. Suh, T. H. Lee, K. S. Choi, K. Hong, Y. G. Song, Y.-S. Shim, M. Shokouhimehr, C.-Y. Kang, S. Y. Kim and H. W. Jang, ACS Sens., 2019, 4, 678-686.

25 Y. H. Kim, Y. S. Choi, S. Y. Park, T. Kim, S.-P. Hong, T. H. Lee, C. W. Moon, J.-H. Lee, D. Lee, B. H. Hong and H. W. Jang, Nanoscale, 2019, 11, 2966-2973.

26 Y. H. Kim, K. C. Kwon, S. Kang, C. Kim, T. H. Kim, S.-P. Hong, S. Y. Park, J. M. Suh, M.-J. Choi, S. Han and H. W. Jang, ACS Sens., 2019, 4, 2395-2402.

27 J. M. Suh, Y.-S. Shim, K. C. Kwon, J.-M. Jeon, T. H. Lee, M. Shokouhimehr and H. W. Jang, Electron. Mater. Lett., 2019, 15, 368-376.

28 S. Y. Park, Y. H. Kim, S. Y. Lee, W. Sohn, J. E. Lee, Y.-S. Shim, K. C. Kwon, K. S. Choi, H. J. Yoo, J. M. Suh, M. Ko, J.-H. Lee, M. J. Lee, S. Y. Kim, M. H. Lee and H. W. Jang, J. Mater. Chem. A, 2018, 6, 5016-5024.

29 W. Zheng, Y. Xu, L. Zheng, C. Yang, N. Pinna, X. Liu and J. Zhang, Adv. Funct. Mater., 2020, 30, 2000435.

30 B. Han, Z. Duan, J. Xu, Y. Zhu, Q. Xu, H. Wang, H. Tai, J. Weng and Y. Zhao, Adv. Funct. Mater., 2020, 30, 2002232.

31 Z. Ma, P. Chen, W. Cheng, K. Yan, L. Pan, Y. Shi and G. Yu, Nano Lett., 2018, 18, 4570-4575.

32 Y. Jiang, N. Tang, C. Zhou, Z. Han, H. Qu and X. Duan, Nanoscale, 2018, 10, 20578-20586.

33 C. H. A. Esteves, B. A. Iglesias, T. Ogawa, K. Araki, L. Hoehne and J. Gruber, ACS Omega, 2018, 3, 6476-6482.

34 N. Barsan and U. Weimar, J. Electroceram., 2001, 7, 143-167.

35 R. Prajesh, N. Jain and A. Agarwal, Microsyst. Technol., 2016, 22, 2185-2192.

36 F. Xu and H.-P. Ho, Micromachines, 2017, 8, 333.

37 E. Espid and F. Taghipour, Crit. Rev. Solid State Mater. Sci., 2017, 42, 146-432.

38 F. Xu, H.-F. Lv, S.-Y. Wu and H.-P. Ho, Sens. Actuators, B, 2018, 259, 709-716.

39 R. Chen, J. Wang, S. Luo, L. Xiang, W. Li and D. Xie, Appl. Catal., B, 2020, 264, 118554.
40 H. Chen, M. Zhang, R. Bo, C. Barugkin, J. Zheng, Q. Ma, S. Huang, A. W. Y. Ho-Baillie, K. R. Catchpole and A. Tricoli, Small, 2018, 14, 1702571.

41 H. Chen, M. Zhang, X. Fu, Z. Fusco, R. Bo, B. Xing, H. T. Nguyen, C. Barugkin, J. Zheng, C. F. J. Lau, S. Huang, A. W. Y. Ho-Baillie, K. R. Catchpole and A. Tricoli, Phys. Chem. Chem. Phys., 2019, 21, 24187-24193.

42 H.-Y. Li, J.-W. Yoon, C.-S. Lee, K. Lim, J.-W. Yoon and J.-H. Lee, Sens. Actuators, B, 2018, 255, 2963-2970.

43 J. Cui, L. Shi, T. Xie, D. Wang and Y. Lin, Sens. Actuators, B, 2016, 227, 220-226.

44 M. R. Alenezi, A. S. Alshammari, K. D. G. I. Jayawardena, M. J. Beliatis, S. J. Henley and S. R. P. Silva, J. Phys. Chem. C, 2013, 117, 17850-17858.

45 I. Cho, Y. C. Sim, M. Cho, Y.-H. Cho and I. Park, ACS Sens., 2020, 5, 563-570.

46 D. A. Melnick, J. Chem. Phys., 1957, 26, 1136.

47 J. T. Cheung, US Pat., US005448906A, 1995.

48 H.-J. Kim and J.-H. Lee, Sens. Actuators, B, 2014, 192, 607-627.

49 N. Yamazoe, G. Sakai and K. Shimanoe, Catal. Surv. Asia, 2003, 7, 63-75.

50 B. Liu, Y. Luo, K. Li, H. Wang, L. Gao and G. Duan, $A d v$. Mater. Interfaces, 2019, 6, 1900376.

51 L. Liu, X. Li, P. K. Dutta and J. Wang, Sens. Actuators, B, 2013, 185, 1-9.

52 R. Kumar, N. Goel and M. Kumar, ACS Sens., 2017, 2, 1744-1752.

53 X. Tian, X. Yang, F. Yang and T. Qi, Colloids Surf., A, 2019, 578, 123621.

54 D. Klaus, D. Klawinski, S. Amrehn, M. Tiemann and T. Wagner, Sens. Actuators, B, 2015, 217, 181-185.

55 M. Kumar, R. Kumar, S. Rajamani, S. Ranwa, M. Fanetti, M. Valant and M. Kumar, Nanotechnology, 2017, 28, 365502.

56 H. Wang, L. Zhou, Y. Liu, F. Liu, X. Liang, F. Liu, Y. Gao, X. Yan and G. Lu, Sens. Actuators, B, 2020, 305, 127498.

57 S. Zhang, L. Zhao, B. Huang and X. Li, Sens. Actuators, B, 2020, 319, 128264.

58 N. D. Chinh, C. Kim and D. Kim, J. Alloys Compd., 2019, 778, 247-255.

59 Y. Chen, X. Li, X. Li, J. Wang and Z. Tang, Sens. Actuators, B, 2016, 232, 158-164.

60 G. Maduraiveeran, M. Sasidharan and W. Jin, Prog. Mater. Sci., 2019, 106, 100574.

61 G. Ingrosso, Microchem. J., 2002, 73, 221.

62 K. R. Marllires, D. Wang, V. V. Tipparaju and N. Tao, IEEE Sens. J., 2019, 19, 8252-8261.

63 B. Wang, W. Huang, L. Chi, M. Al-Hashimi, T. J. Marks and A. Facchetti, Chem. Rev., 2018, 118, 5690-5754.

64 X.-X. Wang, H.-Y. Li and X. Gio, J. Mater. Chem. A, 2020, 8, 14482-14490.

65 E. Espid, A. S. Noce and F. Taghipour, J. Photochem. Photobiol., A, 2019, 374, 95-105.

66 A. Ilin, M. Martyshov, E. Forsh, P. Forsh, M. Rumyantseva, A. Abakumov, A. Gaskov and P. Kashkarov, Sens. Actuators, $B, 2016,231,491-496$. 
67 A. S. Chizkov, M. N. Rumyantseva, R. B. Vasiliev, D. G. Filatova, K. A. Drozdov, I. V. Krylov, A. V. Marchevsky, O. M. Karakulina, A. M. Abakumov and A. M. Gaskov, Thin Solid Films, 2016, 618, 253-262.

68 N. D. Chinh, N. D. Quang, H. Lee, T. T. Hien, N. M. Hieu, D. Kim, C. Kim and D. Kim, Sci. Rep., 2016, 6, 35066.

69 R. Jaisutti, J. Kim, S. K. Park and Y.-H. Kim, ACS Appl. Mater. Interfaces, 2016, 8, 20192-20199.

70 S. C. Chang, J. Vac. Sci. Technol., 1980, 17, 366-369.

71 Y. Nakamura, Y. Ishikawa, Y. Morita, H. Takagi and S. Fujitsu, Sens. Actuators, B, 2013, 187, 578-585.

72 S. Park, S. An, Y. Mun and C. Lee, ACS Appl. Mater. Interfaces, 2013, 5, 4285-4292.

73 G. Lu, J. Xu, J. Sun, Y. Yu, Y. Zhang and F. Liu, Sens. Actuators, B, 2012, 162, 82-88.

74 E. Wongrat, N. Chanlek, C. Chueaiarrom, B. Samransuksamer, N. Hongsith and S. Choopun, Sens. Actuators, A, 2016, 251, 188-197.

75 F. H. Saboor, T. Ueda, K. Kamada, T. Hyodo, Y. Mortazavi, A. A. Khodadadi and Y. Shimizu, Sens. Actuators, B, 2016, 223, 429-439.

76 A. Berholts, T. Kahro, A. Floren, H. Alles and R. Jaaniso, Appl. Phys. Lett., 2014, 105, 163111.

77 X. Geng, C. Zhang, M.-G. Olivier and M. Debliquy, Proceedings, 2017, 1, 411.

78 K. T. Alali, J. Liu, J. Yu, D. Moharram, R. Chen, H. Zhang, Q. Liu, M. Zhang and J. Wang, J. Alloys Compd., 2020, 832, 154999.

79 Q. A. Drmosh, A. H. Hendi, M. K. Hossain, Z. H. Yamani, R. A. Moqbel, A. Hezam and M. A. Gondal, Sens. Actuators, B, 2019, 290, 666-675.

80 V. Paolucci, S. M. Emamjomeh, L. Ottaviano and C. Cantalini, Sensors, 2019, 19, 2617.

81 M. Reddeppa, B.-G. Park, G. Murali, S. H. Choi, N. D. Chinh, D. Kim, W. Yang and M.-D. Kim, Sens. Actuators, B, 2020, 308, 127700.

82 W. Zhang, Z. Huang, W. Zhang and Y. Li, Nano Res., 2014, 7, 1731-1737.

83 G. Chen, T. M. Paronyan, E. M. Pigos and A. R. Harutyunyan, Sci. Rep., 2012, 2, 343.

84 D. Gu, X. Li, H. Wang, M. Li, Y. Xi, Y. Chen, J. Wang, M. N. Rumyntseva and A. M. Gaskov, Sens. Actuators, B, 2018, 256, 992-1000.

85 D. Gu, X. Wang, W. Liu, X. Li, S. Lin, J. Wang, M. N. Rumyantseva, A. M. Gaskov and S. A. Akbar, Sens. Actuators, B, 2020, 305, 127455.

86 S. R. Damkale, S. S. Arbuj, G. G. Umarji, R. P. Panmand, S. K. Khore, R. S. Sonawane, S. B. Rane and B. B. Kale, Sustainable Energy Fuels, 2019, 3, 3406-3414.

87 E. Huang, X. Yao, W. Wang, G. Wu, N. Guan and L. Li, ChemPhotoChem, 2017, 1, 60-69.

88 Y. Huang, W. Jiao, Z. Chu, G. Ding, M. Yan, X. Zhong and R. Wang, J. Mater. Chem. C, 2019, 7, 8616.

89 D. J. Late, Y.-K. Huang, B. Liu, J. Acharya, S. N. Shirodkar, J. Luo, A. Yan, D. Charles, U. V. Waghmare and V. P. Dravid, ACS Nano, 2013, 7, 4879-4891.
90 E. Comini, A. Cristalli, G. Faglia and G. Sberveglieri, Sens. Actuators, B, 2000, 65, 260-263.

91 K. Anothainart, M. Burgmair, A. Karthigeyan, M. Zimmer and I. Eisele, Sens. Actuators, B, 2003, 93, 580-584.

92 J. Wang, H. Deng, X. Li, C. Yang and Y. Xia, Sens. Actuators, $B, 2020,304,127317$.

93 H. Chen, Y. Chen, H. Zhang, D. W. Zhang, P. Zhou and J. Huang, Adv. Funct. Mater., 2018, 28, 1801035.

94 X. Geng, C. Zhang and M. Debliquy, Ceram. Int., 2016, 42, 4845-4852.

95 S. Park, G.-J. Sun, H. Kheel, T. Ko, H. W. Kim and C. Lee, Appl. Phys. A: Mater. Sci. Process., 2016, 122, 504.

96 Z. Yang, L. Guo, B. Zu, Y. Guo, T. Xu and X. Dou, Adv. Opt. Mater., 2014, 2, 738-745.

97 S. Park, S. An, H. Ko, S. Lee and C. Lee, Sens. Actuators, B, 2013, 188, 1270-1276.

98 A. S. Chizhov, M. N. Rumyantseva, R. B. Vasiliev, D. G. Filatova, K. A. Drozdov, I. V. Krylov, A. M. Abakumov and A. M. Gaskov, Sens. Actuators, B, 2014, 205, 305-312.

99 S. Park, S. An, Y. Mun and C. Lee, Curr. Appl. Phys., 2014, 14, 557-562.

100 A. S. Chizhov, M. N. Rumyantseva, R. B. Vasiliev, D. G. Filatova, K. A. Drozdov, I. V. Krylov, A. V. Marchevsky, O. M. Karakulina, A. M. Abakumov and A. M. Gaskov, Thin Solid Films, 2016, 253-262.

101 G. Magna, A. Catini, R. Kumar, M. Palmacci, E. Martinelli, R. Paolesse and C. D. Natale, Sensors, 2017, 17, 747.

102 S. Nasirian, Appl. Surf. Sci., 2020, 502, 144302.

103 M. Reddeppa, T. Chandrakalavathi, B.-G. Park, G. Murali, R. Siranjeevi, G. Nagaraju, J. S. Yu, R. Jayalakshmi, S.-G. Kim and M.-D. Kim, Sens. Actuators, B, 2020, 307, 127649.

104 G. Giorgi, J.-I. Fujisawa, H. Segawa and K. Yamashita, J. Phys. Chem. C, 2014, 118, 12176.

105 Y. Zhuang, W. Yuan, L. Qian, S. Chen and G. Shi, Phys. Chem. Chem. Phys., 2017, 19, 12876.

106 M. Zhang, J. S. Yun, Q. Ma, J. Zheng, C. F. J. Lau, X. Deng, J. Kim, D. Kim, J. Seidel, M. A. Green, S. Huang and A. W. Y. Ho-Baillie, ACS Energy Lett., 2017, 2, 438-444.

107 J. K. Nam, D. H. Chun, R. J. K. Rhee, J. H. Lee and J. H. Park, Adv. Sci., 2018, 5, 1800509.

108 S. Sergeyev, W. Pisula and Y. H. Geerts, Chem. Soc. Rev., 2007, 36, 1902-1929.

109 J. E. Anthony, A. Facchetti, M. Heeney, S. R. Marder and X. W. Zhan, Adv. Mater., 2010, 22, 3876-3892.

110 M. El Gemayel, M. Treier, C. Musumeci, C. Li, K. Müllen and P. Samorì, J. Am. Chem. Soc., 2012, 134, 2429-2433.

111 Y. Li, H. Jin, G. Sun, B. Zhang, N. Luo, H. Bala, J. Cao, Z. Zhang and Y. Wang, Phys. E, 2019, 106, 40-44.

112 E. Espid, B. Adeli and F. Taghipour, J. Electrochem. Soc., 2019, 166, H3223-H3230.

113 T. Dilova, G. Atanasova, A. O. Dikovska and N. N. Nedyalkov, Appl. Surf. Sci., 2020, 505, 144625.

114 C. Chen, Q. Zhang, G. Xie, M. Yao, H. Pan, H. Du, H. Tai, X. Du and Y. Su, Mater. Res. Express, 2020, 7, 015924.

115 J. Wang, S. Fan, Y. Xia, C. Yang and S. Komarneni, J. Hazard. Mater., 2020, 381, 120919. 
116 Y. Yao, F. Ji, M. Yin, X. Ren, Q. Ma, J. Yan and S. F. Liu, ACS Appl. Mater. Interfaces, 2016, 8, 18165-18172.

117 Q. Zhang, G. Xie, M. Xu, Y. Su, H. Tai, H. Du and Y. Jiang, Sens. Actuators, B, 2018, 259, 269-281.

118 Y. Zhou, C. Zou, X. Lin and Y. Guo, Appl. Phys. Lett., 2018, 113, 082103.

119 Y. Yao, M. Yin, J. Yan, D. Yang and S. Liu, Sens. Actuators, B, 2017, 251, 583-589.

120 Y. Sun, Y. Sun, T. Zhang, G. Chen, F. Zhang, D. Liu, W. Cai, Y. Li, X. Yang and C. Li, Nanoscale, 2016, 8, 10774-10782.

121 K. Liu, Y. Bi, S. Qu, F. Tan, D. Chi, S. Lu, Y. Li, Y. Kou and Z. Wang, Nanoscale, 2014, 6, 6180-6186.

122 S. K. Cushing, J. Li, F. Meng, T. R. Senty, S. Suri, M. Zhi, M. Li, A. D. Bristow and N. Wu, J. Am. Chem. Soc., 2012, 134, 15033-15041.

123 S. J. Han, S. K. Kim, A. Hwang, S. Kim, D.-Y. Hong, G. Kwak, K.-W. Jun and Y. T. Kim, Appl. Catal., B, 2019, 241, 305-318.

124 D. Wu, K. Deng, B. Hu, Q. Lu, G. Liu and X. Hong, ChemCatChem, 2019, 11, 1598-1601.
125 Z. L. Wang, J. Phys.: Condens. Matter, 2004, 16, R829-R858.

126 M. E. Franke, T. J. Koplin and U. Simon, Small, 2005, 2, 36-50.

127 L. E. Greene, B. D. Yuhas, M. Law, D. Zitoun and P. Yang, Inorg. Chem., 2006, 45, 7535-7543.

128 Z. L. Wang, Mater. Sci. Eng., 2009, 64, 33-71.

129 J. Herran, O. Fernandez-Gonzalez, I. Castro-Hurtado, T. Romero, G. G. Mandayo and E. Castano, Sens. Actuators, $B, 2010,149,368-372$.

130 C.-L. Hsu, L.-F. Chang and T.-J. Hseuh, Sens. Actuators, B, 2017, 249, 265-277.

131 O. Casals, N. Markiewicz, C. Fabrega, I. Gracia, C. Cane, H. S. Wasisto, A. Waag and J. D. Prades, ACS Sens., 2019, 4, 822-826.

132 N. Markiewicz, O. Casals, C. Fabrega, H. S. Wasisto, A. Waag and J. D. Prades, Proceedings, 2018, 2(13), 971.

133 J. D. Prades, R. Jimenez-Diaz, M. Manzanares, F. HernandezRamirez, A. Cirera, A. Romano-Rodriguez, S. Mathur and J. R. Morante, Phys. Chem. Chem. Phys., 2009, 11, 10881-10889. 